\title{
3 Research Square

\section{Anisotropy analysis for optimized gas production in Coalbed Methane reservoir, Bokaro field, India}

\author{
Abir Banerjee ( $\sim$ Banerjee_Abir@ongc.co.in ) \\ Oil and Natural Gas Corporation Limited, Bokaro, India

\section{Rima Chatterjee} \\ Indian Institute of Technology (Indian School of Mines), Dhanbad, India

\section{Dip Kumar Singha} \\ Banaras Hindu University, Varanasi, India
}

\section{Research Article}

Keywords: Anisotropy, Dewatering, Dispersion, Stress orientation, Resistivity Image

Posted Date: June 3rd, 2021

DOl: https://doi.org/10.21203/rs.3.rs-582910/v1

License: (1) This work is licensed under a Creative Commons Attribution 4.0 International License. Read Full License

Version of Record: A version of this preprint was published at Geophysical Prospecting on June 13th, 2022. See the published version at https://doi.org/10.1111/1365-2478.13236. 
1 Anisotropy analysis for optimized gas production in Coalbed Methane

2 reservoir, Bokaro field, India

$3 \quad{ }^{1}$ Abir Banerjee, ${ }^{2}$ Rima Chatterjee, ${ }^{3}$ Dip Kumar Singha

4 1. Oil and Natural Gas Corporation Limited, Bokaro, Jharkhand-827001, India

5 2. Dept. of Applied Geophysics, IIT(ISM) Dhanbad, Jharkhand- 826004, India

6 3. Department of Geophysics, Banaras Hindu University, Varanasi, India

7 Corresponding Author email: Banerjee_Abir@ongc.co.in

8

9

Corresponding author:

Abir Banerjee

Senior Geoscientist

Department of Well Logging

Jharkhand-827001, India 


\section{Abstract}

The efficient production of Coalbed Methane (CBM) gas is facing challenges due to the larger dewatering period from fracture connectivity to the aquifer zone. Also, commingled production from well makes it more difficult to identify the coal seam-wise problem. Therefore, prior knowledge of sub-surface fractures in coal seams is necessary to execute an accurate simulation model for planning hydraulic fracturing treatment. This paper highlights the studies in Bokaro CBM reservoir to mitigate challenges in few wells by characterizing anisotropy, determining fast shear wave polarization angle, maximum horizontal stress direction, fracture orientation, and analysis of low resistivity signature. Both the fast shear wave polarization angle and fracture orientation in resistivity image are observed in the same direction $\left(\mathrm{N} 26^{\circ}-\right.$ $35^{\circ} \mathrm{E}$ ) in coal. The fast and slow shear slowness versus frequency plot concludes stress-induced anisotropy resulting from fractures that are supported by resistivity image and drilling core. Processing of the resistivity image log shows the maximum horizontal stress is along NE-SW direction, as identified from drilling-induced fractures. The observation of low resistivity signature with resistivity ranging from 0.4 to $0.8 \mathrm{ohm}-\mathrm{m}$ in few wells confirms the presence of conducting minerals such as siderite and pyrite from the x-ray diffraction studies of sidewall core. The present work guides in making production, drilling, and hydraulic fracturing design strategies to better understand the fluid propagation for optimized CBM production and will also help in future geomechanical studies.

\section{Keywords}

Anisotropy; Dewatering; Dispersion; Stress orientation; Resistivity Image

\section{Highlights}

- Anisotropy analysis and characterization in coalbed methane reservoir. 
47 - Fractures, cleats and drilling-induced fractures identification from resistivity image log.

- Determination of maximum horizontal stress direction.

- Investigation of low resistivity signature from x-ray diffraction studies.

- Implication on the production process for CBM reservoir development.

\section{Introduction}

Coalbed methane (CBM) gas is becoming an alternate energy resource from the last decade in exploration and consumption viewpoint. India is among the fifth largest producer and has proven coal reserves in the world (Chatterjee et al. 2019). Exploration of CBM has many challenges and needs proper planning and technologies for extracting methane gas (Paschin and Groshong 1998; Bell and Bachu 2003). Coal has low permeability and the methane gas production increases significantly with presence of naturally occurring fractures, cleats and joints in imbedding sandstone and shale (Pitman et al. 2003; Chatterjee and Paul 2013). However, primary permeability from natural fractures and cleats are not sufficient for the production process, therefore hydraulic fracturing $(\mathrm{HF})$ treatment in a coal seam is necessary to create fractures for secondary permeability.

Anisotropy is an occurrence where the physical properties vary directionally in a medium. Anisotropy can be two types: one is the intrinsic type due to the preferred mineral or grain deposition as platy nature of thin isotropic layer and another is stress-induced anisotropy appeared from initiation of fracture alignment (Wang 2002). The physical properties vary in the horizontal or vertical plane with the borehole axis, it is known as Vertical Transverse Isotropy (VTI), observed in shale or thinly bedded intervals (Cheng and Cheng 1996; Wang 2002). Pore structure, fabric, and stress are the concern of anisotropy. Coal matrix deformation is related to the pore structure and fabric coal resulting from CBM gas adsorption/desorption. 
70 The presence of opening mode fractures; face and butt cleats in coal is connected to stress-

71 induced anisotropy. Stress-induced anisotropy is derived from the S-wave velocities using advanced sonic logging data indicates azimuthal anisotropy or horizontal transverse isotropy (HTI) due to the variation of physical properties in the azimuthal direction around the wellbore (Stevens and Day 1986; Cheng and Cheng 1996). The anisotropy mechanisms can be distinguished and characterized through radial acoustic dispersion analysis (Plona et al. 2000; Moreno et al. 2013).

In the petroleum industry, the anisotropy results are widely used for the optimization of reservoir drainage, fault, and fracture detection and characterization in open hole, to forecast borehole instability, design well, and evaluate well completion process for optimizing gas production (Klimentos 2003; Franco et al. 2005). Properties of each compressional (P), shear (S), and Stoneley (St) wave are affected by anisotropy in the formation. S-wave is influenced by azimuthal anisotropy, St-wave responds to VTI anisotropy is established but P-wave is least affected by anisotropy (Hornby et al. 1999; Sun et al. 2003). The dipole flexural S-mode is affected and it gives erroneous results due to borehole failure or breakouts in an elliptical borehole (Grandi et al. 2003). During data processing, the higher relative dip angle between the borehole axis and formation beds is necessary to be considered (Tang and Patterson 2005; De and Schmitt 2005).

Analysis of stress-dependent coal anisotropy is conducted for studying and determining the gas flow and directional permeability in coal (Feng et al. 2019). Unconventional energy sources like CBM, the anisotropy analysis is performed in the characterization of fractures and determination of stress direction for well designing and estimating the permeable direction for CBM reservoir simulation (Hower 2003; Feng et al. 2019). The occurrence of azimuthal anisotropy from fractures in coal is established using seismic data was shown by many authors 
94 (De et al. 1998; Gray et al. 2002; Vetri et al. 2003). Processing of cross multipole array acoustics log data is required to know the dispersion characteristics of S-waves with frequency for its identification of stress-induced and intrinsic anisotropy. Stress direction is required for geomechanical application, oriented perforation, and effective fracturing in objective formations (Fletcher et al. 1996; Todorovic-Marinic et al. 2004).

In a previous study on west Bokaro Coalfield (CF), the resistivity image log has identified the Breakouts (BOs) oriented along $\mathrm{N} 60^{\circ} \mathrm{W}$ and drilling-induced fractures (DIFs) oriented along $\mathrm{N} 15^{\circ} \mathrm{E}$ to $\mathrm{N} 35^{\circ} \mathrm{E}$, that are an important indicator of minimum $\left(\mathrm{S}_{\mathrm{h}}\right)$ and maximum $\left(\mathrm{S}_{\mathrm{H}}\right)$ horizontal stress direction (Paul et al. 2017). But, in this CF, anisotropy analysis and its characterization were not performed using sonic log, and the literature survey has not mentioned the presence of a low resistivity signature (LRS). The objectives of this study are (a) to analyze and characterize anisotropy using advanced sonic log, (b) to determine stress direction and fracture orientations in coal seams, (c) to analyze the presence of the LRS in few wells, and (d) to address the outcome of this work in assisting future planning for optimized CBM production.

\section{Study Area}

The Bokaro district in the Jharkhand state of eastern India is a part of Damodar valley CF. Lugu hill separates Bokaro CF into east and west. West and east Bokaro CF extend over an area of $180 \mathrm{~km}^{2}$ and $208 \mathrm{~km}^{2}$, respectively (Banerjee and Chatterjee 2021). The Bokaro CF comprising of Gondwana sediments, with dimensions $64 \mathrm{~km}$ x $12 \mathrm{~km}$ (Varma et al. 2014). The study area of west and east Bokaro CF is shown in the geological map with wells (W-2 to W-4 and A-1 to A-4) in figure 1 (Banerjee and Chatterjee 2021). Mahadeva, Panchet, Raniganj, Barren, Barakar, and Talchir are the geological formation in this CF in order from the top. The coal deposits are found in the Barakar and Raniganj Formation. Drilling information have 
reported the presence of 13 coal seams numbered as Seam "XIII to I" in order of descent in Barakar formation in west CF with thickness of 300-550 meters (Murthy et al. 2016). The present work is focused on 05 seams, namely "X, IX, VIII, VII+VII, V". In east CF, major seams are Karo, Bermo, Kargali Bottom, and Kargali Top (KT). The KT seam is focused on east CF.

\section{Figure 1}

\section{Dataset}

Data of 07 wells named W-2, W-3, W-4, A-1, A-2, A-3, and A-4 are available in the study area. All wells contain geophysical logs such as resistivity (RES), gamma-ray (GR), neutron porosity (NEU) and density (DEN). Additionally, resistivity image log in W-2 and W-4, advanced sonic log in $\mathrm{W}-2$, production data of $\mathrm{W}-2, \mathrm{~W}-3$, and $\mathrm{W}-4$, drilling core (356.0 $\mathrm{m}$ to $362.5 \mathrm{~m}$ ) in W-2 and X-ray diffraction (XRD) studies of sidewall core (SWC) samples in A-1 are available. The lithologies such as coal, shale, and sandstone are identified based on the geophysical well logs cut-off criteria (Banerjee and Chatterjee 2021). In coal seam, GR (30-80 API), RES (900-50000 ohm-m), DEN (1.45-1.8 g/cc), and NEU (45-65\%) are the range of geophysical parameters. Figure 2 represents the geophysical log response of well W-2 and objective coal seams are marked in the density log.

\section{Figure 2}

\section{Production Process and Problems}

The routine operational activities include the perforation of coal seam followed by hydraulic fracturing (HF) treatment. Subsequently, the perforated and HF coal seams are pumped continuously using an artificial pumping machine for dewatering and gas production.

Dewatering extracts the water volume from the coal seam to desorb the existing gas in an adsorbed state by achieving the critical desorption pressure. Once the critical desorption 
pressure is attained, the gas break occurs (Sun et al. 2017). Initially, only water is produced without gas, but once gas breaks are attained, water production declines, and gas production increases. A longer dewatering period is the challenge for cost optimization. The commingled production from 05 seams with the period (days) shows larger dewatering $\left(\mathrm{m}^{3} /\right.$ day) and smaller discontinuous gas break ( $\left.\mathrm{m}^{3} / \mathrm{day}\right)$ in $\mathrm{W}-2$ and $\mathrm{W}-3$, whereas in well $\mathrm{W}-4$ no gas break is observed (Figures 3a, 3b, 3c). The water and gas production in these 03 wells are different as wells are drilled in different locations at different times but the recording interval of production data is constant as shown in figure 3. Well W-2 is recorded from February 2019 to October 2019, but no major gas break is observed, hence the well was closed. Similarly, well W-3 is recorded from 2017 to 2019 but the well was closed from January 2018 to January 2019 due to well complication, after that it was again recorded with the observation of few discontinuous gas breaks. The production data in well W-4 from September 2018 to June 2019 shows no gas break and hence the well was closed. The average duration of production in these $03 \mathrm{CBM}$ wells was continued for 6-8 months as discontinuous/no gas breaks were observed.

\section{Figure 3}

\section{Mathematical Background}

The shear wave splitting phenomenon into fast and slow S-wave represents anisotropy in the formation. Let us consider a multi-source and multi-receiver system where S-wave splitting occurs. The splitting of the S-wave may or may not coincide with the natural coordinate system (Crampin 1981; Thomsen 1988). In figure 4, S1 and S2 are the directions, and v1 and v2 are the velocities of fast and slow $S$-wave in multiple sources and receiver systems. $S_{a}(t)$ and $S(t)$ are the source matrix in the acquisition and natural coordinate system. $S_{R}(t)$ and $S_{T}(T)$ represents the radial and transverse sources in the acquisition coordinate. The relationship 
between these components are expressed in the form of the equation using vector rotation matrix $\mathrm{R}(\theta)$ :

167

$$
\left(\begin{array}{cc}
\cos \theta & \sin \theta \\
-\sin \theta & \cos \theta
\end{array}\right)\left(\begin{array}{cc}
S_{R} & 0 \\
0 & S_{T}
\end{array}\right)=\left(\begin{array}{cc}
S_{R} \cos \theta & S_{T} \sin \theta \\
-S_{R} \sin \theta & S_{T} \cos \theta
\end{array}\right)
$$

168 Where $\mathrm{S}_{\mathrm{a}}(\mathrm{t})=\left(\begin{array}{cc}S_{R} & 0 \\ 0 & S_{T}\end{array}\right), \mathrm{S}(\mathrm{t})=\left(\begin{array}{cc}S_{R} \cos \theta & S_{T} \sin \theta \\ -S_{R} \sin \theta & S_{T} \cos \theta\end{array}\right)$ and $\mathrm{R}(\theta)=\left(\begin{array}{cc}\cos \theta & \sin \theta \\ -\sin \theta & \cos \theta\end{array}\right)$,

169 Similarly the reflected signal $\mathrm{V}(\mathrm{t})$ is recorded in the acquisition coordinate, that is expressed as:

171 Where $\mathrm{V}(\mathrm{t})=\left(\begin{array}{cc}U_{11} \cos \theta & -U_{22} \sin \theta \\ U_{11} \sin \theta & U_{22} \cos \theta\end{array}\right)$, and $\mathrm{U}(\mathrm{t})=\left(\begin{array}{cc}U_{11} & 0 \\ 0 & U_{22}\end{array}\right)$, represents matrix in the natural

172 coordinate system, $\mathrm{U}_{11}$ and $\mathrm{U}_{22}$ is the reflected signal along $\mathrm{S} 1$ and $\mathrm{S} 2$ direction.

173 The above equation from time domain to frequency domain is expressed as:

175 Where $D(\omega)=\left(\begin{array}{cc}f_{1}(\omega) e^{-i \omega \delta_{1}} & 0 \\ 0 & f_{2}(\omega) e^{-i \omega \delta_{2}}\end{array}\right)$ represent time-delay function of the fast and slow Swave, $\delta_{1}$ and $\delta_{2}$ are the two-way travel time, and $\mathrm{f} 1$ and $\mathrm{f} 2$ are the filter function for the fast and

177 slow S-wave set for the attenuation, geometric spreading, and reflection coefficient.

178 By applying rotation in data matrix in both source and receiver coordinate, the output of rotated 179 data matrix is expressed as:

180 $D(\omega) \bullet S_{a}(\omega)=D(\omega) \bullet R^{-1}(\theta) \bullet D^{-1}(\omega) \bullet R(\theta) \bullet V(\omega)=W(\omega)$, 
$182 W(\omega)=\left(\begin{array}{ll}w_{R R} & w_{R T} \\ w_{T R} & w_{T T}\end{array}\right)=\left(\begin{array}{cc}\cos ^{2} \theta+\sin ^{2} \theta e^{+i \omega \Delta} & \sin \theta \cos \theta-\sin \theta \cos \theta e^{+i \omega \Delta} \\ \sin \theta \cos \theta e^{-i \omega \Delta}-\sin \theta \cos \theta & \sin ^{2} \theta e^{-i \omega \Delta}+\cos ^{2} \theta\end{array}\right) \bullet\left(\begin{array}{ll}v_{R R} & v_{R T} \\ v_{T R} & v_{T T}\end{array}\right)$ $183 \quad,(6)$

184 Where in $\mathrm{W}_{\mathrm{RT}}$ and $\mathrm{V}_{\mathrm{RT}}, \mathrm{R}$ represents receiver direction and $\mathrm{T}$ represents transmitter direction,

185 and $\Delta=2 z\left(\frac{1}{\beta_{2}}-\frac{1}{\beta_{1}}\right)$. The multiplication factor $\mathrm{e}^{ \pm \mathrm{i} \omega \Delta}$ is the time shift factor from frequency to 186 time domain.

187 Hence, equation (6) determines the angle $(\theta)$ between fast $S$-wave and acquisition line, and the 188 time lag $(\Delta)$ between fast and slow $\mathrm{S}$-wave, the acquisition matrix data $\mathrm{V}(\mathrm{t})$ can be rotated into $189 \mathrm{~W}(\mathrm{t})$ for separating fast and slow S-wave. Parameters $(\theta, \Delta)$ is computed by searching and 190 rotating the input data by a set of range in angles and time, and the normalization of off191 diagonal elements of the rotated matrix is expressed as:

192

$\square e_{i j}(\theta, \Delta, t) \square_{p}=\left(\sum_{k=1}^{N}\left|w_{i j}(\theta, t+k \Delta t)\right|^{p}\right)^{\frac{1}{p}}$,

193 Where $\mathrm{N}$ represents samples number in the search window and $\mathrm{k}$ and $\mathrm{p}$ are the integers.

\section{Methods}

196

The flowchart of integrated work to determine and characterize anisotropy, to understand subsurface fracture system, stress direction, and to study core and production data using available data is presented in figure 5. The reason for larger dewatering and less/no gas break are analyzed from anisotropy analysis. LRS is observed below KT seam is concluded from the XRD study. 
The advanced sonic tool has two sets of 8 acoustically isolated orthogonal receivers and two sets of acoustically isolated orthogonal transmitters (Harrison et al. 1990; Brie et al. 1997). Each receiver set receives either inline or cross-line (orthogonal) waveform for one transmitter signal. Four waveform components, two inline and two cross-line dipoles are recorded for anisotropy analysis (Bechham 1996; Walls et al. 1996). Alford rotation is applied to the waveform to establish the orientation of fast and slow S-waves (Alford 1986). The resulting waveform is processed using a cross-correlation technique called semblance processing for getting fast and slow S-wave slowness (Kimball and Marzetta 1986; Esmersoy et al. 1994), represented in black line shown in projection log from depth interval $407.0-427.0 \mathrm{~m}$ in well W-2 (Figure 6) and its output is applied to obtain the fast S-wave polarization angle and energy anisotropy.

In coal, fast and slow S-wave slowness varies from 130-170 us/ft and 130-160 us/ft respectively. The anisotropy in coal seams is analyzed from three types of indicators: (a) energy anisotropy, (b) travel time (TT) anisotropy, and (c) slowness (DTS) anisotropy. Energy anisotropy is determined from the percentage of the cross-dipole components relative to all four components, the minimum, and maximum cross line energy at each depth are calculated. The strength of the anisotropy is measured from the difference of maximum with minimum cross-energy (Vasquez 2016). The TT and DTS anisotropy are calculated from the differences in travel time and slowness between fast and slow principle waveform. The TT is obtained 223 from first arrival picking of slowness waveform and DTS anisotropy is obtained by dividing the slowness difference by averaging fast and slow S-slowness to obtain the percentage difference (Vasquez 2016). 


\subsection{S-wave dispersion analysis}

228

229

Acoustic anisotropy is recognized from waveform components processing results but the cause for anisotropy in the formation cannot be determined. To determine the cause, slowness vs. frequency dispersion is obtained to extract the information. Four types of acoustic anisotropy mechanisms can be identified through radial acoustic dispersion analysis in the formation: (a) Homogeneous isotropic (b) Inhomogeneous isotropic (c) Homogeneous anisotropic and (d) Inhomogeneous anisotropic. The four types of mechanisms are shown in figure 7 (Plona et al. 2000; Moreno et al. 2013). No S-wave splitting occurs over frequency in a homogeneous isotropic medium (Figure 7a). In an inhomogeneous isotropic medium, no S-wave splitting occurs but slowness data are higher compared to the predictive model (Figure $7 \mathrm{~b}$ ). In a homogeneous anisotropic medium, parallel splitting of fast and slow S-wave slowness is observed; this mechanism is associated with intrinsic anisotropy: the layering of fractures (Figure 7c). In inhomogeneous anisotropic medium splitting of fast and slow S-wave slowness is associated with crossover (Figure 7d), associated with the stress-induced anisotropy around the wellbore.

\section{Figure 7}

\subsection{Resistivity image analysis}

The resistivity image log acquired from a high-resolution resistivity tool in water-based mud is checked to ensure quality and speed correction is applied to analyze logging tool response while acquiring the data. Processed image generated is equalized and normalized to obtain static and dynamic images of the sub-surface formations. The resistivity image of the wellbore is represented in a color spectrum ranging from low to high resistivity value in a flat surface in the clockwise (North-East-South-West-North) direction of the wellbore. In static images, 
resistivity color spectrum remains constant with depth, whereas, in dynamic image, enhanced resistivity image spectrum with depth is generated.

In the image log, drilling-induced fractures (DIFs) and borehole breakouts (BOs) are the indicators of the present-day stress direction (Barton et al. 1998; Barton and Zoback 2002; Ali et al. 2017). BOs corresponds to the $S_{h}$ direction occurs due to low mud weight, is not observed in this study whereas DIFs are observed as a thin vertical pair of line at $180^{\circ}$ apart in image $\log$, correspond to the $\mathrm{S}_{\mathrm{H}}$ direction which occurs due to high mud weight (Bell and Gough 1979; Trautwein-Bruns et al. 2010). Fractures are observed as a sinusoidal curve in the image log. Cleats are the natural fractures present in coal seam observed as small vertical to subvertical lines and transverse lines in image log due to regional tectonic stress and internal tectonic stress (Paschin et al. 1991; Laubach et al. 1998; Pitman et al. 2003). Features such as DIFs, fractures, cleats, and coal bed are identified along with its azimuth and dip magnitude are obtained in five coal seams in well W-2 and W-4. The resistivity image log is processed to pick the dip magnitude. The magnitude is calculated from the following formula:

$$
d i p=\tan ^{-1}\left(\frac{h}{d}\right),
$$

Where $\mathrm{h}$ is the height of crest and trough in meters, $\mathrm{d}$ is the borehole diameter in meters.

\subsection{Low resistivity signatures (LRS) analysis}

LRS is observed below the KT coal seam, which is set as a marker in few wells in east Bokaro CF. Conventional resistivity logs in wells A-1, A-2, A-3, and A-4 are correlated and LRS signature was observed (Figure 8). Resistivity in the LRS zone ranges from 0.4-0.8 ohm-m. To investigate the LRS, SWC was extracted in A-1 at depth $418.0 \mathrm{~m}$ and XRD studies were 
conducted in the laboratory. Also, conducting fractures are observed in the resistivity image log in well A-2 against the LRS.

\subsection{Error analysis}

\section{Figures 8}

Error analysis is the measure of accuracy that identifies and detects uncertainty in the result.

The error in degree is obtained from the difference in the observed and predicted magnitude of fast S-wave polarization direction. Hence, the error is plotted with depth for seam "X, IX, VIII, VI+VII, and V" (Figures 9a, 9b, 9c, 9d, 9e). The root mean square (RMS) technique is used to estimate the error. RMS error of 05 coal seams is calculated from the square root of the sum of standard deviation between observed and predicted magnitude in figure 9. Mathematically, the equation of RMS error is defined as:

$R M S_{-}$error $=\sqrt{\frac{\sum_{d=1}^{n}\left(x_{o b s}-x_{p r e d}\right)^{2}}{n}}$,

where $\mathrm{X}_{\mathrm{obs}}$ is the observed magnitude of fast $\mathrm{S}$-wave direction, $\mathrm{x}_{\mathrm{pred}}$ is the predicted model magnitude of fast $\mathrm{S}$-wave direction, $\mathrm{d}$ is the depth points considered for calculation from 1 to $\mathrm{n}$ in each seam.

\section{Results and Discussion}

Anisotropy is estimated from S-wave in well W-2 by applying the Alford rotation technique and fast $\mathrm{S}$-wave polarization direction is determined in 05 objective coal seams. The fast Swave polarization angle and fracture orientation are observed in the same direction in coal seam. In coal, the average energy anisotropy varies from $10-80 \%$, TT and DTS anisotropy range from $0-20 \%$ and $0-15 \%$. Figure 10 represents seam-VIII that illustrates energy anisotropy 
with maximum/minimum energy ranges from 50-65\% / 10-30\%, TT and DTS anisotropy varies from $0-10 \%$ and $0-15 \%$. Fast S-wave polarizes along $\mathrm{N} 60^{\circ} \mathrm{E}$ and $\mathrm{S} 60^{\circ} \mathrm{W}$. The S-slowness versus frequency dispersion cross-plot indicates stress-induced anisotropy in the wellbore at 19 depth points, intrinsic anisotropy at single depth point, and rest depth intervals are observed to be homogeneous isotropic. In this work, three depth points in well W-2 marked as (a. at 342.0 $\mathrm{m})$, (b. at $389.0 \mathrm{~m}$ ), and (c. at $437.0 \mathrm{~m}$ ) in fast and slow $\mathrm{S}$-wave log illustrates three cases respectively (Figure 11). The dispersion cross-plot of fast and slow S-waves are shown in red and blue dots in figure 12. Figure 12a represents the depth at $342.0 \mathrm{~m}$ is observed to be a homogeneous isotropic formation. Figure $12 \mathrm{~b}$ represents the depth at $389.0 \mathrm{~m}$ in coal seam-V which is in a stress-induced condition. Figure 12c represents the depth at $437.0 \mathrm{~m}$ that is observed with intrinsic anisotropy in shale. Also, the correlation of anisotropic depths confirms fractured in the resistivity image log.

The $\mathrm{S}_{\mathrm{H}}$ direction is estimated from DIFs in resistivity image from depth interval 618.0-650.0 m is observed along NE-SW (N26 $\left.-35^{\circ} \mathrm{E}\right)$ in W-4 (Figure 13a). The DIF direction obtained in this work matches well with the previous study as $\mathrm{N} 15^{\circ} \mathrm{E}$ to $\mathrm{N} 35^{\circ} \mathrm{E}$ by Paul et al. (2017). Figure $13 \mathrm{~b}$ represents seam-V showing fractures, cleats, and coal bed in W-4 with its dip magnitude and direction. Fractures are also observed in the drilling core at $356.0 \mathrm{~m}$ and $357.5 \mathrm{~m}$, which matches with the resistivity image $\log$ in W-2 (Figure 14). Cleats in coal orients in all directions, but maximum cleats orientation tends toward NE-SW direction along $\mathrm{S}_{\mathrm{H}}$ direction. The dip direction of coal bed varies seam wise but dip magnitude ranges from $15^{\circ}-25^{\circ}$ in $\mathrm{W}-2$ and $1^{\circ}-10^{\circ}$ in $\mathrm{W}-4$. The dip orientation and magnitude of DIFs, fracture, cleats, and coal bed are presented in stereonet plots for W-2 and W-4 (Figures 15a, 15b, 15c and 15d, 15e, 15f, $15 \mathrm{~g}$ ). The detailed analysis of dip magnitude and direction, fast S-wave polarization angle, fracture orientation, cleats azimuth, and coal bed of coal seams "X, IX, VIII, VI+VII, and V" in 
well W-2 and W-4 are tabulated in table 1 . The data in table 1 are significant to establish a seam-wise model. Error in fast S-wave polarization angle in seam "X, IX, VIII, VI+VII and V" are $5.38^{\circ}, 5.15^{\circ}, 4.40^{\circ}, 3.37^{\circ}$, and $4.81^{\circ}$ respectively. The stress direction and fracture orientation play an important role in designing HF treatment as HF fluid propagates along $\mathrm{S}_{\mathrm{H}}$ plane through fractures and connect to the aquifer that leads to larger dewatering. The maximum fluid flow is along $S_{H}$ direction, therefore, seam-wise planning for perforation/oriented perforation for production is required instead of commingled production. HF should be performed only in the least fractured coal seam and it should be avoided in a highly fractured seam. Therefore, highly fractured coal production should be taken after perforation, and if the gas production declines with time then HF should be executed. The working guide to steer the trajectory for drilling horizontal/inclined well to pass through $\mathrm{S}_{\mathrm{h}}$ direction cutting maximum numbers of cleats and fractures that will enhance the natural flow of fluids through increased connectivity between cleats and fractures. Additionally, stability of horizontal/inclined wellbore increases if its trajectory passes through $\mathrm{S}_{\mathrm{h}}$ direction.

The stress-induced anisotropic model in CBM reservoir will help in preparing the directional mechanical earth model by integrating core and empirical geomechanical models. It will establish a relationship in the directional variation of rock-mechanical properties in understanding fracture extension and fluid propagation in coal seam during HF treatment. Lack of core and geomechanical studies are the constraints for accurate design and implementation of HF simulation model where rock-mechanical properties act as an important input parameter for obtaining fracture parameters and volume of proppants requirement for pumping in a coal seam. Previously, HF fluid movement could not be restricted within coal seams and has propagated beyond the coal seams connecting the aquifer zone leading to a larger dewatering 
period with less/no gas production. It occurs due to approximation and uncertainty in the simulation model which impacts cost economics and delays in target achievement.

The XRD studies of SWC samples in LRS formation below KT seam in east Bokaro CF confirms the deposition of conductive minerals such as siderite and pyrite in fractures from (Figure 16). Identification of low resistivity signatures is acting as a marker below KT coal seam helps in well correlation. The lower part of $\mathrm{KT}$ seam requires proper planning in $\mathrm{HF}$ treatment. The corroboration of finding of fracture, fast S-wave direction, slowness frequency dispersion cross-over or $\mathrm{S}_{\mathrm{H}}$ direction between sonic, resistivity image, and core data suggests the correctness of processing results. The robustness of the result will increase with the presence of advanced sonic, resistivity image, and core data in other wells.

\section{Figure 13, 14, 15, 16, and Table 1}

\section{Conclusions}

The outcome of the study assist in optimized gas production in CBM reservoir from the following conclusions:

(1) Anisotropy is analyzed from travel time delay of fast and slow shear wave. The fast shear wave polarization direction, fracture orientation, and $\mathrm{S}_{\mathrm{H}}$ direction matched well and are observed along $\mathrm{N} 26^{\circ}-35^{\circ} \mathrm{E}(\mathrm{NE}-\mathrm{SW})$.

(2) Anisotropy associated with a coal seam is stress-induced due to the splitting phenomena in slowness versus frequency plot. The stress-induced anisotropy is associated with the fractures and cleats.

(3) Intrinsic anisotropy is caused due to parallel fractures in shale in Bokaro coalfield.

(4) The reason for the larger dewatering period in wells is due to the fracture extension through HF treatment in the coal seam connecting the aquifer zone. 
367 (5) This work provides vital information for drilling horizontal/inclined well, the production 368 flow path for oriented perforation, coal seam-wise model for operational and production 369 activities.

370 (6) Scope for future studies includes (i) geomechanical studies (ii) effective design for 371 hydraulic fracturing treatment (iii) fracture extension, and (iv) investigation of low resistivity signature in the formation from geological and tectonic activities.

\section{Acknowledgment}

375 The authors are thankful to Oil and Natural Gas Corporation (ONGC) Limited for providing 376 permission to present this paper. The authors also wish to place on record the help and guidance rendered by Mr. A.K Dwivedi (Ex-Director (Exploration), ONGC), and Mr. N.C. Pandey (Ex-Director (T\&FS), ONGC). We thank Mr. Shubham Dimri (technical engineer Emerson-Paradigm), for the technical support in using Geolog software. No funding was received in the preparation of this manuscript.

\section{Data Availability}

382 The data that support the finding of the result in this manuscript is available with the CBM, 383 Bokaro Asset of ONGC, India.

\section{References}

Alford, R. M. (1986). Shear Data in the Presence of Azimuthal Anisotropy: Dilley, Houston, Texas, USA, November 2-6, Paper S9.6. 
Ali, M., Paul, S., \& Chatterjee, R. (2017). Cleat Orientation from Ground Mapping and Image Log Studies for In-Situ Stress Analysis: Coal Bed Methane Exploration in South Karanpura Coalfield, India. Energy \& Fuels, 31, 6812-6824.

Banerjee, A., \& Chatterjee, R. (2021). A Methodology to Estimate Proximate and Gas Content Saturation with Lithological Classification in Coalbed Methane Reservoir, Bokaro Field, India. Natural Resources Research, 30, 2413-2429. https://doi.org/10.1007/s11053-02109828-2

Barton, C., Hickman, S., Morin, R., Zoback, M., \& Benoit D. (1998). Reservoir-scale fracture permeability in the Dixie Valley, Neveda, geotherma field. SPE, ISRM, 47371-27899. https://doi.org/10.2118/47371-MS

Barton, C.A., \& Zoback, M.D. (2002). Discrimination of natural fractures from drilling induced wellbore failures in wellbore image data - implication of reservoir permeability. SPE Reservoir Evaluation and Engineering, SPE 78599, 5(3), 249-254. https://doi.org/10.2118/78599-PA

Beckham, W.E. (1996). Seismic Anisotropy and Natural Fractures from VSP and Borehole Sonic Tools-A Field Study. Geophysics, 61(2), 456-466. http://dx.doi.org/10.1190/1.1443973

Bell, J.S., \& Bachu, S., 2003. In situ stress magnitude and orientation estimates for Cretaceous coal-bearing strata beneath the plains area of central and southern Alberta. Bulletin of Canadian Petroleum Geology, 51(1), 1-28. https://doi.org/10.2113/gscpgbull.51.1.1

Bell, J.S., \& Gough, D.I. (1979). Northeast-southwest compressive stress in Alberta evidence fromoil wells. Earth and Planetary science letters, 45(2), 475-482. https://doi.org/10.1016/0012-821X(79)90146-8 
Brie, A., Kimball, C.V., Pabon, J., \& Saiki, Y. (1997). Shear slowness determination from dipole measurements. In 38 SPWLA Annual International Symposium, Houston, Texas, Society of Professional Well Log Analysts, Paper F, 14.

Chatterjee, R., \& Paul, S. (2013). Classification of Coal Seams for Coal Bed Methane Exploitation in Central Part of Jharia Coalfield, India-A Statistical Approach. Fuel, 111, 20-29. https://doi.org/10.1016/j.fuel.2013.04.007

Chatterjee, R., Paul, S., \& Pal, P.K. (2019). Relation between coalbed permeability and in-situ stress magnitude for coalbed methane exploration in Jharia and Raniganj coalfields, India. The Leading Edge, October, 800-807.

Cheng, N., Cheng, \& C.H. (1996). Estimations of Formation Velocity, Permeability and Shear-Wave Velocity Using Acoustic Logs. Geophysics, 61(2), 437-443. http://dx.doi.org/10.1190/1.1443971.

Crampin, S., \& Lowell, J. (1991). A decade of shear-wave splitting in the Earth's crust: what does it mean? what use can we make of it? and what should we do next? Geophysics Journal International, 107, 387-407.

De, G.S., \& Schmitt, D.P., 2005. Issues with Shear-wave Azimuthal Anisotropy in Highly Deviated Wells. In Offshore Technology Conference, Houston, Texas, 2-5May, 2005. OTC-17647-MS. http://dx.doi.org/10.4043/17647-MS

De, G.S., Winterstein, D.F., Johnson, S.J., Higgs, W.G., \& Xiao, H. (1998). Predicting natural and induced fractures azimuths from shear wave anisotropy. SPE Reservoir Evaluation \& Engineering, August, 311-318. https://doi.org/10.2118/50993-PA

Esmersoy, C., Koster, K., Williams, M., Boyd, A., \& Kane, M. (1994). Dipole shear anisotropy logging. In Expanded Abstract, SEG 64th Annual International Meeting. 
Feng, R., Chen, S., \& Bryant, S. (2019). Investigation of Anisotropic Deformation and Stress-Dependent Directional Permeability of Coalbed Methane Reservoirs. Rock Mechanics and Rock Engineering, 1-15. https://doi.org/10.1007/s00603-019-01932-3.

Feng, R., Chen, S., Bryant, S., \& Liu, J. (2019). Stress-dependent permeability measurement techniques for unconventional gas reservoirs: Review, evaluation, and application. Fuel, 256, paper no. 115987.

Fletcher, P.A., Montgomery, C.T., \& Ramos, G.G. (1996). Using fracturing as a technique for controlling formation failure. SPE 27899, 11, 2. https://doi.org/10.2118/27899-PA

Franco, J.L.A., de la Torre, H.G., Ortiz, M.A.M. et al., (2005). Using Shear-Wave Anisotropy To Optimize Reservoir Drainage And Improve Production In LowPermeability Formations in the North of Mexico, Presented at the SPE Annual Conference and Technical Exhibition, Dallas, Texas; 9-12 October, 2005. SPE96808-MS. http://dx.doi.org/10.2118/96808-MS

Grandi, S.K. et al., (2003). In Situ Stress Modeling at a Borehole - A Case Study, paper BH 1.4, Expanded Abstracts, Annual Meeting Technical Program, SEG, 297-300.

Gray, D., Roberts, G., \& Head, K.J. 2002. Recent Advances in Determination of Fracture Strike and Crack Density from P-Wave Seismic Data. The Leading Edge, 21(3), 280-285. https://doi.org/10.1190/1.1463778

Harrison, A.R., Randall, C.J., Aron, J.B., Morris, C.F., Wignall, A.H., \& Dworak, R.A. (1990). Acquisition and analysis of sonic waveforms from a borehole monopole and dipole source for compressional and shear speeds and their relation to rock mechanical properties and surface seismic data. In paper SPE 20557, 65th SPE Annual Technical Conference and Exhibition, New Orleans, September 23-26, 1990. 
Hornby, B., Howie, J., \& Ince, D. (1999). Anisotropy Correction for Deviated Well Sonic Logs- Application to Seismic Well Tie, paper BH/RP 4.7. Expanded Abstracts, Annual Meeting Technical Program, SEG. 1999; 112-115.

Hower, T.L. (2003). Coalbed Methane Reservoir Simulation: An Evolving Science. In paper SPE 84424 presented at the SPE Annual Technical Conference and Exhibition, Denver, Colorado, 5-8 October, 2003. https://doi.org/10.2118/84424-MS

Kimball, C.V., \& Marzetta, T.L. (1986). Semblance processing of borehole acoustic array data. Geophysics, 49(3), 274-281.

Klimentos, T. (2003). Shear-Wave Anisotropy Applications for Perforation Strategy and Production Optimization in Oil Bearing Porous Sands. In paper LL. Trans., Annual Logging Symposium, SPWLA, 1-12, 2003.

Laubach, S.E., Marrett, R.A., Olson, J.E., \& Scott, A.R. (1998). Characteristics and origins of coal cleat: A review. International Journal of Coal Geology, 35, 175-207. https://doi.org/10.1016/S0166-5162(97)00012-8.

Moreno, A., Rodriguez, G., Herrera, R.P., Perez, S., \& Dip, G. (2013). Acoustic radial Measurements Improve Fracture Characterization in Carbonate of South Mexico, Case study: Cretaceous fractured carbonates in Navegate Field. Society of Petroleum Engineers, Second South American Oil and Congress, SPE-WVS-73, Porlamar, Margarita Island, Venezuela.

Pashin, J.C., \& Groshong, Jr. R.H. (1998). Structural control of coalbed methane production in Alabama. International Journal of Coal Geology, 38, 89-113. 
Pashin, J.C., Ward, W.E.I.I., Winston, R.B. et al., (1991). Regional analysis of the Black Creek-Cobb coalbed methane target interval Black Warrior basin, Alabama. Alabama Geological Survey Bulletin, 145, 127.

Paul, S., Ali, M., \& Chatterjee, R., (2017). Prediction of Compressional Wave Velocity Using Regression and Neural Network Modeling and Estimation of Stress Orientation in Bokaro Coalfield, India. Pure and applied Geophysics, 175(1), 375-388.

Pitman, J.K., Pashin, J.C., Hatch, J.R., \& Goldhaber, M.B. (2003). Origin of minerals in joint and cleat systems of the Pottsville Formation, Black Warrior basin, Alabama: Implications for coalbed methane generation and production. AAPG Bulletin, 87(5), $713-731$.

Plona, T., Sinha, B., Kane, M., \& Viloria, O. (2000). Using Acoustic Anisotropy, $40^{\text {th }}$ Annual SPWLA Logging Symposium; 2000.

Stevens, J.L., \& Day, S.M. (1986). Shear Velocity Logging in Slow Formations Using the Stoneley Wave. Geophysics, 51(1), 137-147. http://dx.doi.org/10.1190/1.1442027 22.

Sun, Y. et al., (2003). Effects of Stress-Induced Anisotropy on Monopole and Dipole Logging. In paper RBG P1.2. Expanded Abstracts, Annual Meeting Technical Program, SEG, 1282-1285.

Sun, Z., Li, X., Shi, J., Yu, P., Huang, L., Xia, J., et al. (2017). A semi-analytical model for drainage and desorption area expansion during coal-bed methane production. Fuel, 204, 214-26. https://doi.org/10.1016/j.fuel.2017.05.047

Tang, X.M., \& Patterson, D. (2005). Characterizing Seismic Anisotropy Using CrossDipole Measurement in Deviated Wells. In paper BG 2.5, Expanded Abstracts, Annual Meeting Technical Program, SEG, 372 - 375. 
Thomsen, L. (1988). Reflection seismology in azimuthally anisotropic media. Geophysics, 53, 3, 304-313.

Todorovic-Marinic, D., Larson, D., Gray, D., Cheadle, S., Soule, G., \& Zheng, Y. (2004). Identifying vertical productive fractures in the Narraway gas field using the envelope of the anisotropic gradient. First Break, 22, 10.

Trautwein-Bruns, U., Schulze, K.C., Becker, S., Kukla, P.A., \& Urai, J.L. (2010). In situ stress variations at the variscan deformation front - results from the deep Aachen geothermal well. Techtonophysics, 493(1-2), 196-211. https://doi.org/ 10.1016/j.tecto.2010.08.003.

Varma, A.K., Hazra, B., Samad, S.K., Panda, S., \& Mendhe, V.A. (2014). Methane sorption dynamics and hydrocarbon generation of shale samples from West Bokaro and Raniganj basins, India, Journal of Natural Gas Science and Engineering, 21, 1138-1147.

Vasquez, D. (2016). Optimize Full Waveform Sonic Processing. Paradigm Technical Session, May $18^{\text {th }} ; 2016$.

Vetri, L., Loinger, E., Gaiser, J., Grandi, A., \& Lynn, H. (2003). 3D/4C Emilio: Azimuth processing and anisotropy analysis in a fractured carbonate reservoir. The Leading Edge, 22(7), 675-679. https://doi.org/10.1190/1.1599695

Walls, J.D., Dvorkin, J., \& Mavko, G. (1996). In-Situ Stress Magnitude and Azimuth from Well Log Measurements. Final Report, Chicago, Illinois: Gas Research Institution, Report GRI-95/0356, 1-147.

Wang, Z. (2002). Seismic Anisotropy in Sedimentary Rocks, Part 1 - A Single-Plug Laboratory Method, Part 2 - Laboratory Data. Geophysics, 67(5), 1415-1440. 


\section{Figure Captions}

534 Figure 1. The geological map of the Bokaro coalfield. (After Banerjee and Chatterjee, 2021).

535 Figure 2. Geophysical well logs (GR, RES, DEN, NEU) response from depth interval 115.0$536 \quad 450.0 \mathrm{~m}$ in well $\mathrm{W}-2$.

537 Figure 3. Dewatering $\left(\mathrm{m}^{3} /\right.$ day) and gas $\left(\mathrm{m}^{3} /\right.$ day) production profile versus period (days) in 538 wells (a) W-2 (b) W-3 (c) W-4.

539 Figure 4. Diagram representing S-wave splitting in multi-source and multi-receiver 540 acquisition.

541 Figure 5. Flowchart displaying the steps followed in the integrated work.

542 Figure 6. Slowness picking in black line of fast and slow S-wave from projection log after 543 semblance analysis in well W-2.

544 Figure 7. Classification of acoustic anisotropy from the fast shear (red line) and slow shear 545 (blue line) wave in slowness versus frequency plot. (a) Homogeneous isotropic (b) 
547 (redrawn after Moreneo et al., 2013).

548 Figure 8. Correlation of low resistivity signature (LRS) shown in the red rectangular box 549 below KT coal seam in the resistivity log of 04 wells (A-1, A-2, A-3, A-4).

Figure 9. The error with depth point in (a) Seam-X (b) Seam-IX (c) Seam-VIII (d) SeamVI+VII and (e) Seam-V.

552

Figure 10. Anisotropy analysis representing seam-VIII in well W-2 illustrates maximum and minimum energy (\%), DTS and TTS anisotropy (\%), fast and $180^{\circ}$ apart S-azimuth, resistivity image with dip.

Figure 11. Fast and slow S-wave slowness (us/ft) from depth interval 115.0-450.0 $\mathrm{m}$ in well W-2 and 03 points $(a, b, c)$ marked in the log for anisotropy characterization.

Figure 12. Slowness vs. frequency dispersion plot of fast (red) and slow (blue) S-wave at three depths: (a) Homogeneous isotropic formation at depth $342.0 \mathrm{~m}$ (b) Stress-induced fractured coal seam-V with inhomogeneous anisotropic characteristics at depth $389.0 \mathrm{~m}$ (c) Intrinsic anisotropy for homogeneous anisotropic formation at depth $437.0 \mathrm{~m}$.

Figure 13. Static and dynamic resistivity image in well W-4 (a) represents DIFs with dip magnitude and direction from 622.0-628.0 m, (b) represents dip magnitude and direction of fractures and cleat in seam- $\mathrm{V}$ from depth interval 444.0-452.0 $\mathrm{m}$.

Figure 14. Correlation of fractures at $356.0 \mathrm{~m}$ and $357.5 \mathrm{~m}$ between drilling core and resistivity image log from depth $356.0 \mathrm{~m}$ to $362.5 \mathrm{~m}$.

Figure 15. Stereonet plot representing dip magnitude and direction of 05 seams (V, VI+VII, VIII, IX, X) in well W-2 (a) fracture (b) cleats (c) coal bed; and in well W-4 (d) fracture (e) cleats (f) coal bed, (g) DIFs. 
569

570

571

572

573

574

575

576

577

578

579

Figure 16. Cross-plot of intensity (cps) versus $2 \Theta$ (degree) from the XRD studies of SWC at $418.0 \mathrm{~m}$ in well A-1 showing the presence of siderite and pyrite.

1

\section{Table caption}

8 Table 1. Comparison of dip and azimuth in 05 coal seams between different features in well W-2 and W-4.

\begin{tabular}{|c|c|c|c|c|c|}
\hline \multicolumn{6}{|c|}{ Well: W-2 } \\
\hline Seam & $\begin{array}{c}\text { Depth } \\
\text { interval (m) }\end{array}$ & $\begin{array}{c}\text { Fast } S- \\
\text { wave } \\
\text { direction }\end{array}$ & $\begin{array}{c}\text { Fracture } \\
\text { dip/azimuth }\end{array}$ & $\begin{array}{c}\text { Cleats } \\
\text { azimuth }\end{array}$ & $\begin{array}{c}\text { Coal bed } \\
\text { Dip/azimuth }\end{array}$ \\
\hline $\mathrm{X}$ & $235.0-242.5$ & $\mathrm{~N} 75^{\circ} \mathrm{W}$ & $\begin{array}{c}35^{\circ} / \mathrm{N}^{\circ} 5^{\circ}- \\
85^{\circ} \mathrm{E}\end{array}$ & E and NW-SE & $30^{\circ} / \mathrm{NE}$ \\
\hline IX & $264.5-266.5$ & $\mathrm{~N} 15^{\circ} \mathrm{W}$ & $50^{\circ} / \mathrm{N} 45^{\circ} \mathrm{E}$ & Varies $360^{\circ}$ & $50^{\circ} / \mathrm{NW}$ \\
\hline VIII & $332.0-336.5$ & $\mathrm{~S} 60^{\circ} \mathrm{W}$ & $\begin{array}{c}35^{\circ} / \mathrm{S} 35^{\circ}- \\
65^{\circ} \mathrm{W}\end{array}$ & EW & $35 \% \mathrm{SW}$ \\
\hline VI+VII & $385.0-390.5$ & $\mathrm{~N} 40^{\circ}-65^{\circ} \mathrm{E}$ & $\begin{array}{c}30^{\circ} / \\
\mathrm{N} 45^{\circ} \mathrm{W}- \\
\mathrm{N} 45^{\circ} \mathrm{E}\end{array}$ & NE-SW & $\begin{array}{c}30^{\circ} / \mathrm{N} 30^{\circ} \mathrm{E} \text { (Top) } \\
35^{\circ} / \mathrm{N} 25^{\circ} \mathrm{W} \\
\text { (Bottom) }\end{array}$ \\
\hline $\mathrm{V}$ & $413.0-420.7$ & $\mathrm{~N} 25^{\circ}-60^{\circ} \mathrm{E}$ & $25^{\circ} / \mathrm{N} 20-25^{\circ} \mathrm{E}$ & $\mathrm{NE}$ and $\mathrm{W}$ & $\begin{array}{c}15^{\circ} / \mathrm{N} 50^{\circ} \mathrm{W} \text { (Top) } \\
25^{\circ} / \mathrm{N} 25^{\circ} \mathrm{E} \\
\text { (Bottom) }\end{array}$ \\
\hline
\end{tabular}




\begin{tabular}{|c|c|c|c|c|c|}
\hline \multicolumn{2}{|c|}{ Xell: W-4 } \\
\hline X & $210.0-223.0$ & - & $8^{\circ} / \mathrm{E}$ & NE-SW & $\begin{array}{c}8^{\circ} / \mathrm{SW} \text { (Top) } \\
5^{\circ} / \mathrm{NE} \text { (Bottom) }\end{array}$ \\
\hline IX & $263.5-265.5$ & - & $10^{\circ} / \mathrm{N} 75^{\circ} \mathrm{E}$ & NE-SW and SE & $\begin{array}{c}10^{\circ} / \mathrm{N} \text { (Top) } \\
7^{\circ} / \mathrm{N} 50^{\circ} \mathrm{E} \\
(\mathrm{Bottom})\end{array}$ \\
\hline VIII & $323.0-330.0$ & - & $20^{\circ} / \mathrm{E}$ & NE-SW/NW-SE & $6^{\circ} / \mathrm{E}$ \\
\hline VI+VII & $380.0-384.0$ & - & $60^{\circ} / \mathrm{N} 60^{\circ} \mathrm{W}$ & Varies $360^{\circ}$ & $8^{\circ} / \mathrm{N} 50^{\circ} \mathrm{E}(\mathrm{Top})$ \\
& & & & & $8^{\circ} / \mathrm{E}(\mathrm{Bottom})$ \\
\hline V & $442.0-455.0$ & - & $60^{\circ} / \mathrm{NW}$ & $\mathrm{N} 15^{\circ} \mathrm{E}$ and SW & $1^{\circ} / \mathrm{N} 10^{\circ} \mathrm{E}(\mathrm{Top})$ \\
$8^{\circ} / \mathrm{N} 80^{\circ} \mathrm{E}$ \\
\end{tabular}


Figures

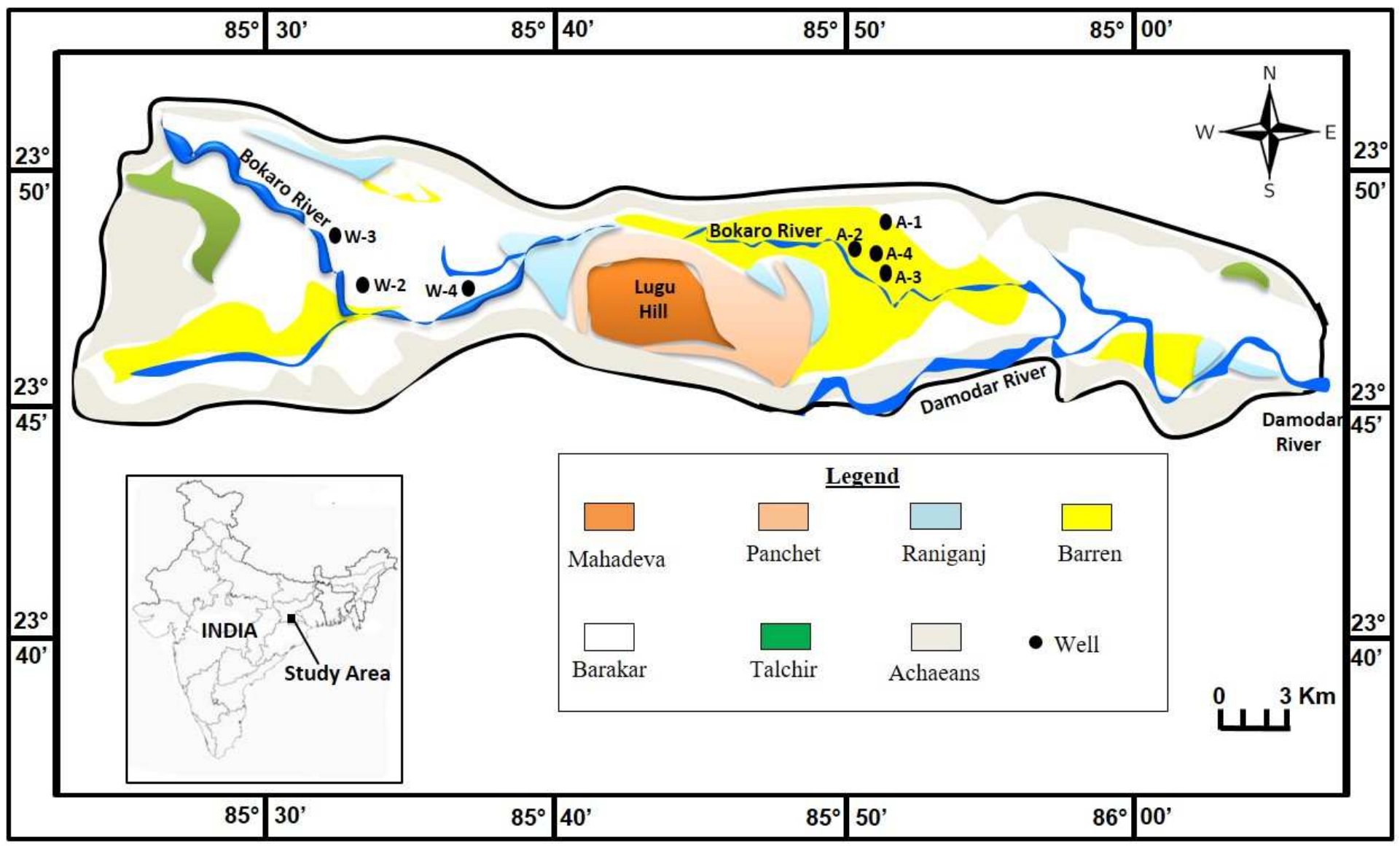

Figure 1

The geological map of the Bokaro coalfield. (After Banerjee and Chatterjee, 2021). 


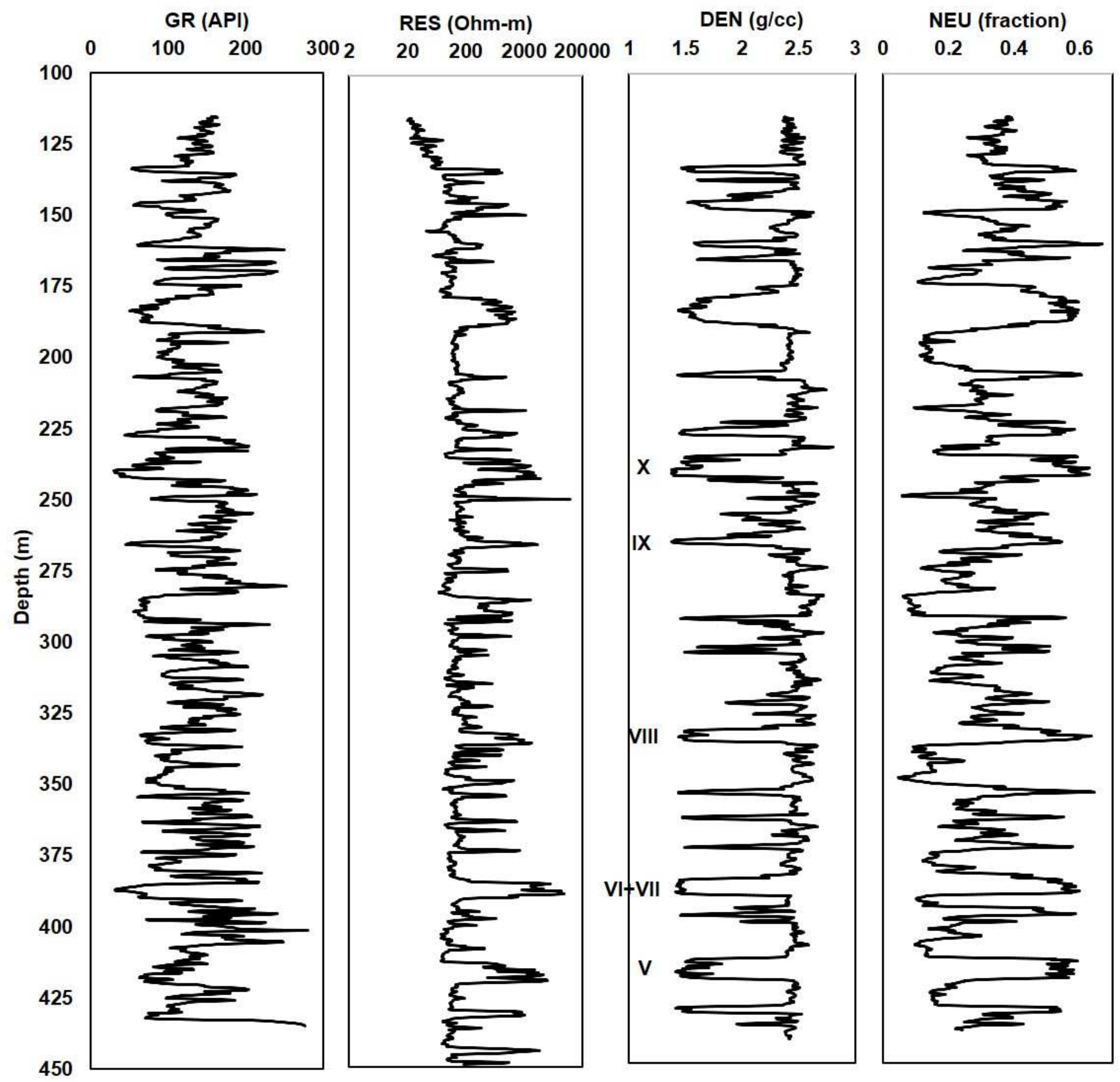

Figure 2

Geophysical well logs (GR, RES, DEN, NEU) response from depth interval 115.0-450.0 m in well W-2. 

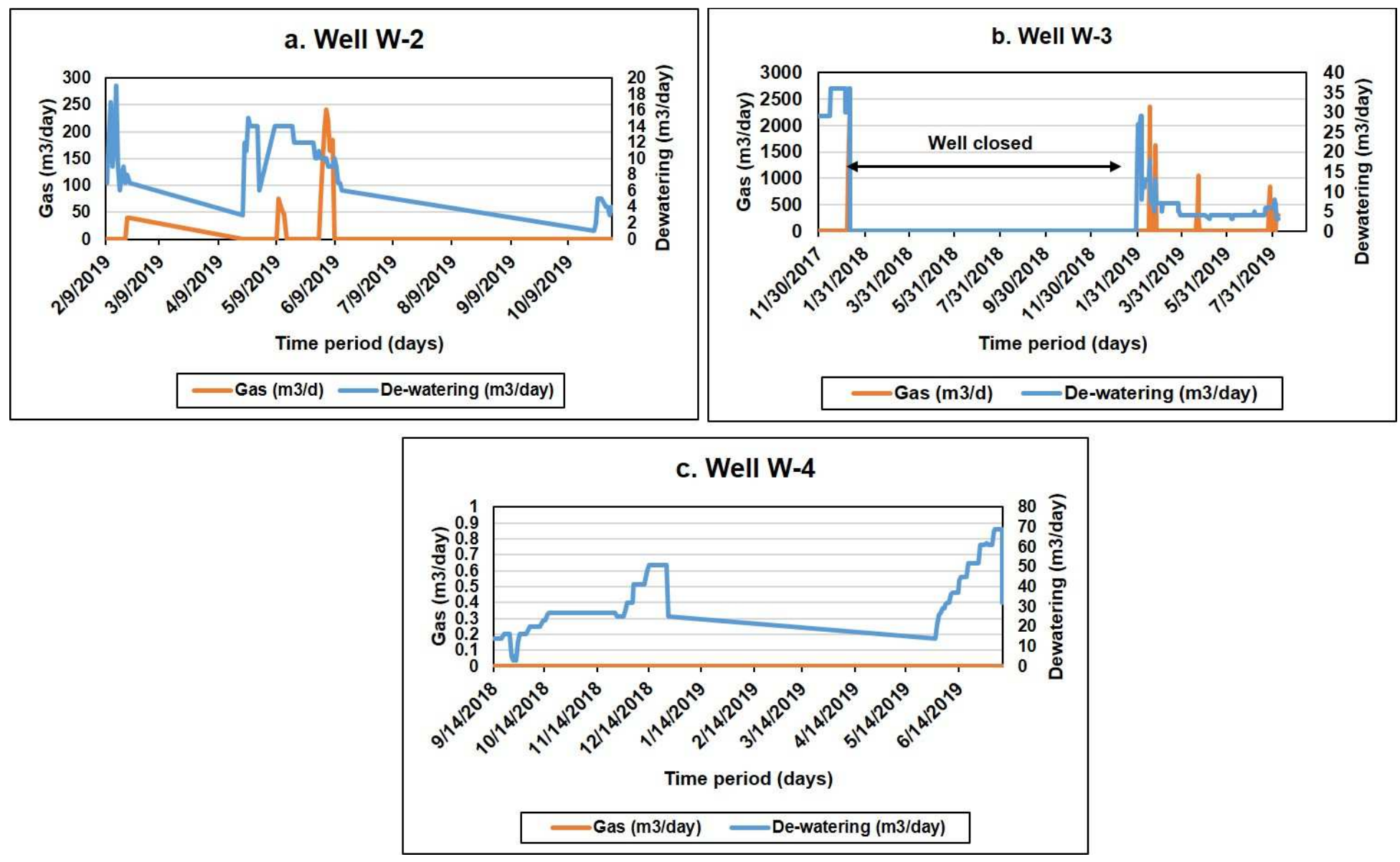

\section{Figure 3}

Dewatering (m3/day) and gas (m3/day) production profile versus period (days) in wells (a) W-2 (b) W-3 (c) W-4.

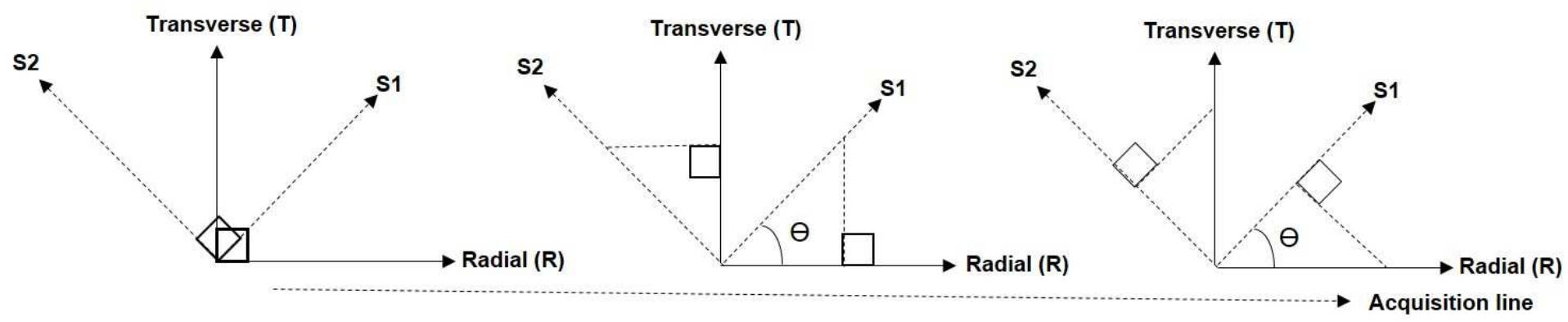

Figure 4

Diagram representing S-wave splitting in multi-source and multi-receiver acquisition. 


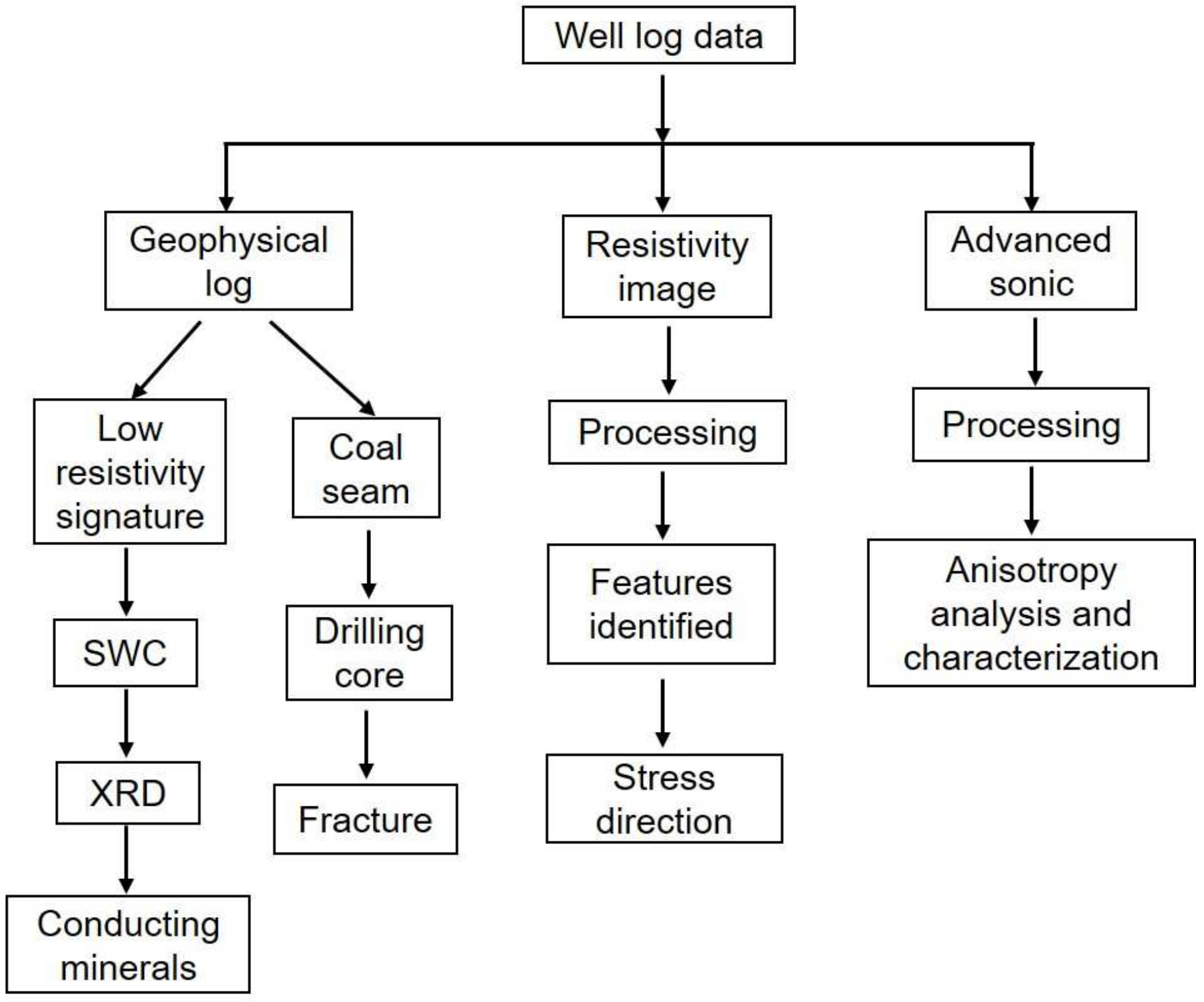

Figure 5

Flowchart displaying the steps followed in the integrated work. 


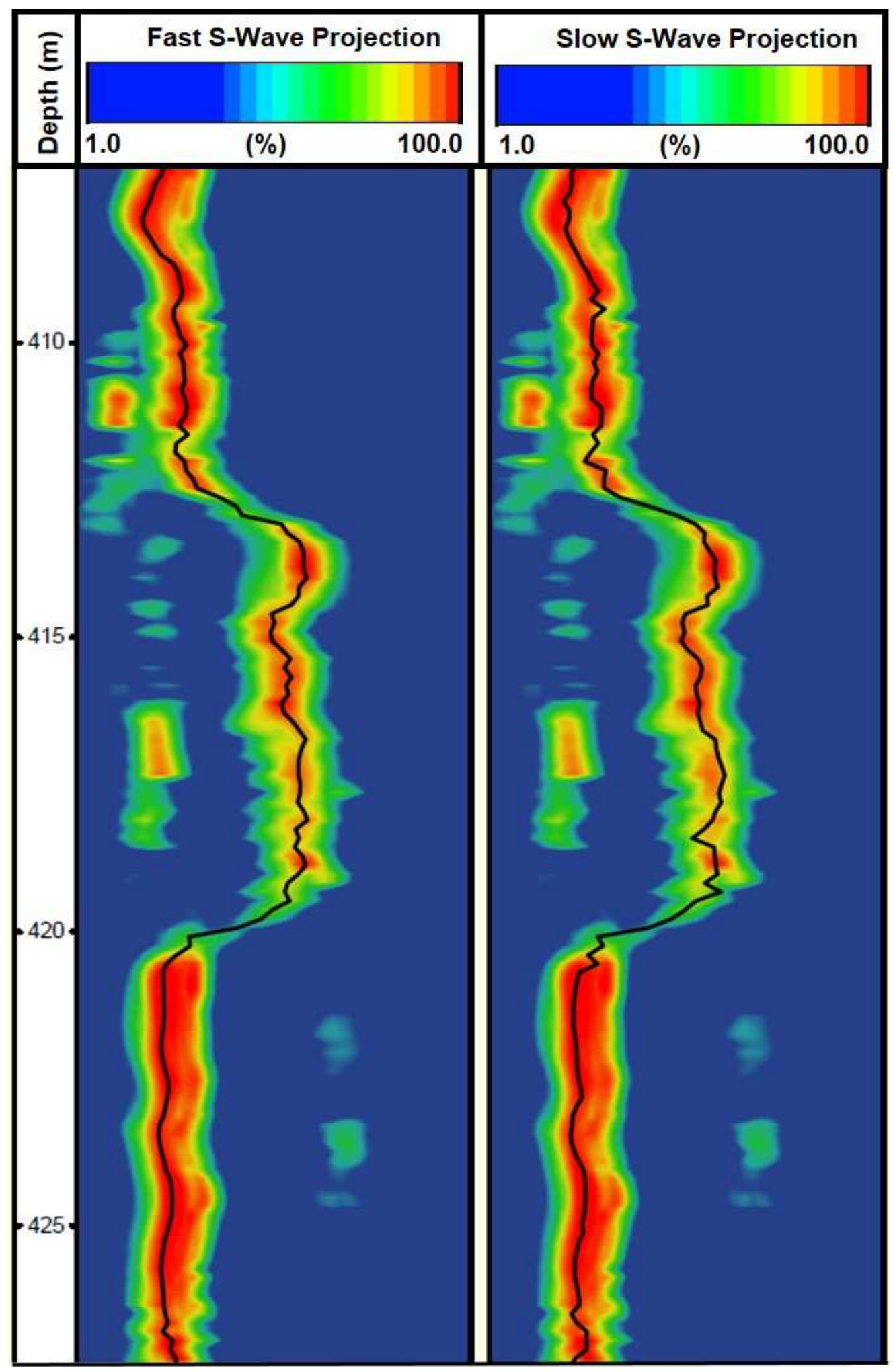

Figure 6

Slowness picking in black line of fast and slow S-wave from projection log after semblance analysis in well W-2. 


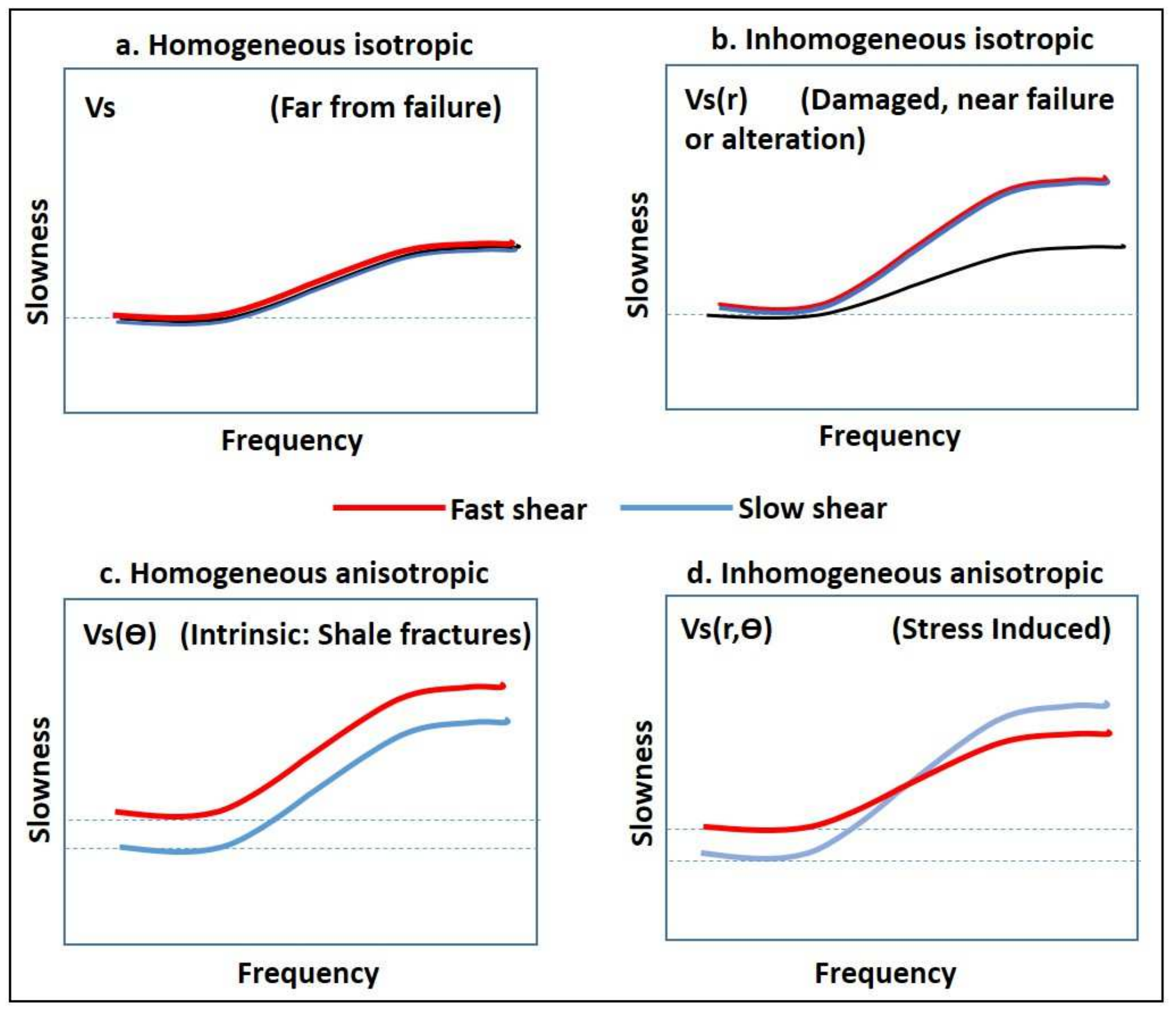

Figure 7

Classification of acoustic anisotropy from the fast shear (red line) and slow shear (blue line) wave in slowness versus frequency plot. (a) Homogeneous isotropic (b) Inhomogeneous isotropic (c) Homogeneous anisotropic (d) Inhomogeneous anisotropic (redrawn after Moreneo et al., 2013). 


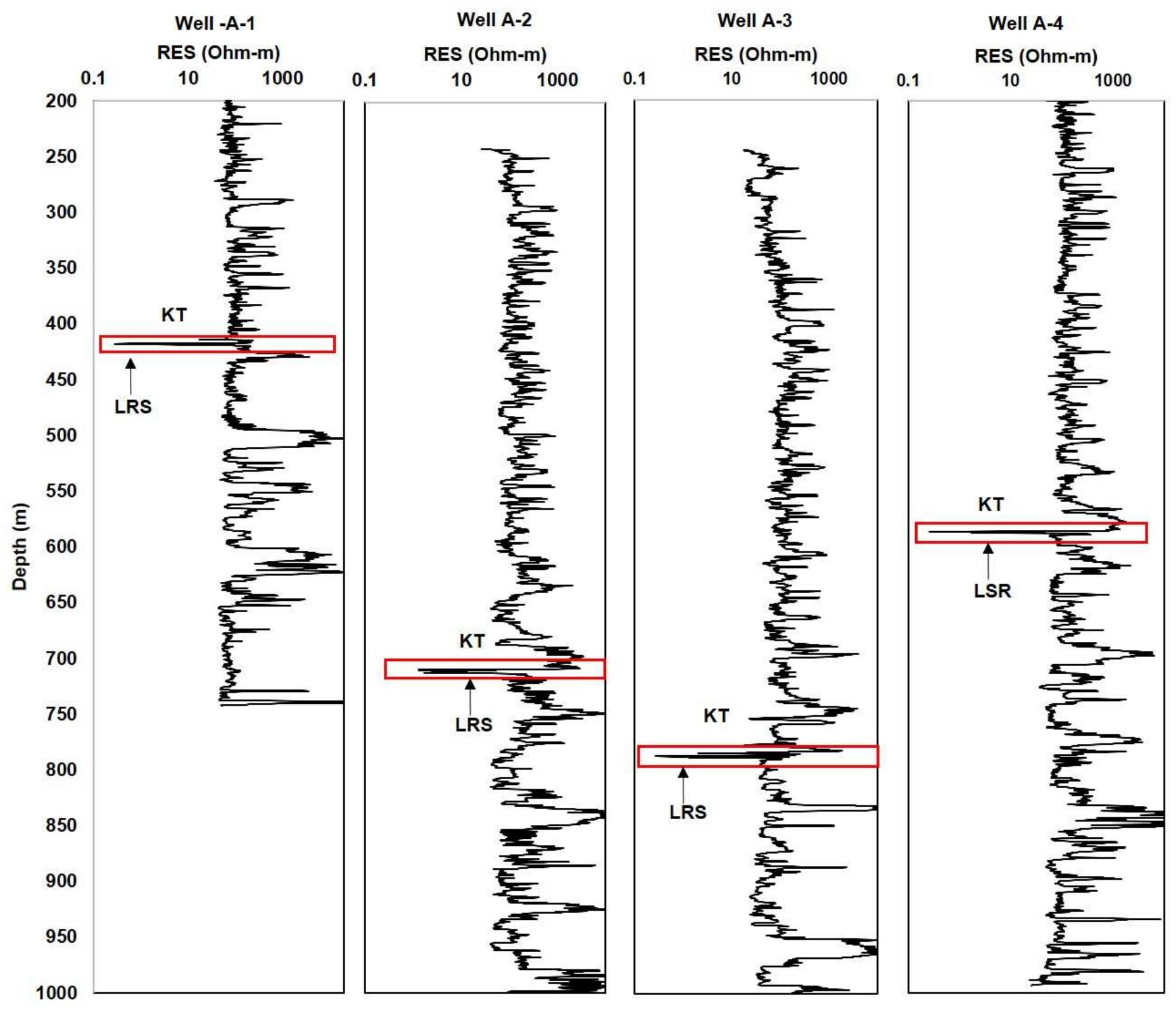

Figure 8

Correlation of low resistivity signature (LRS) shown in the red rectangular box below KT coal seam in the resistivity log of 04 wells (A-1, A-2, A-3, A-4). 

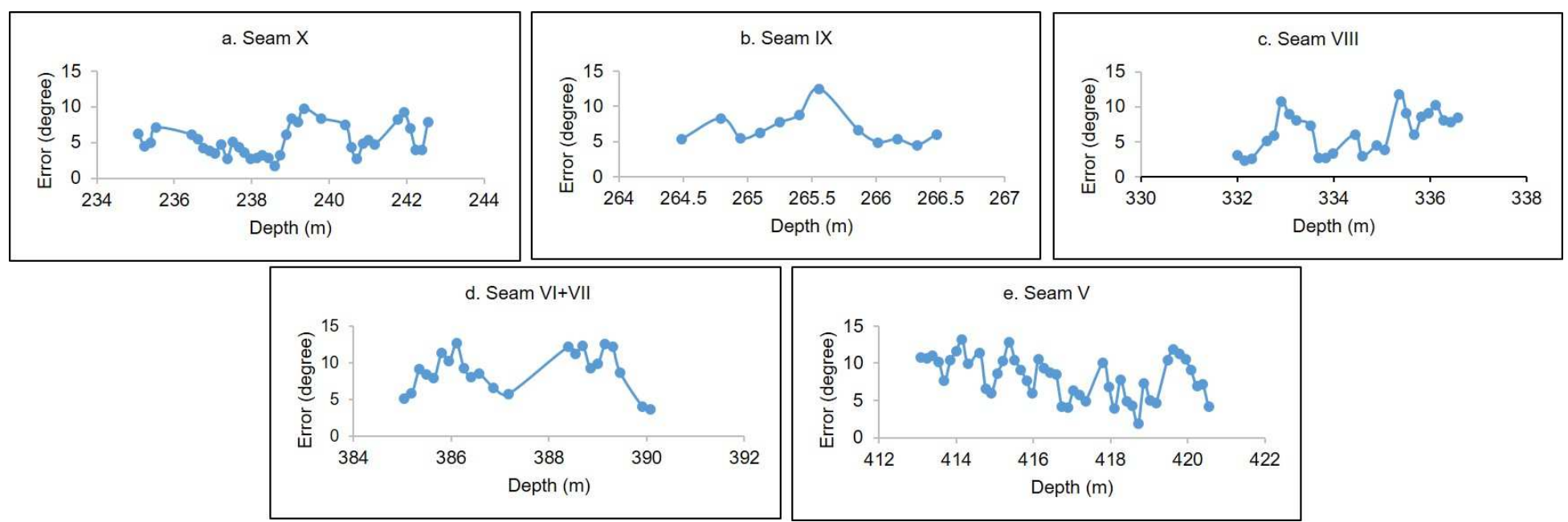

Figure 9

The error with depth point in (a) Seam-X (b) Seam-IX (c) Seam-VIII (d) Seam-VI+VII and (e) Seam-V.

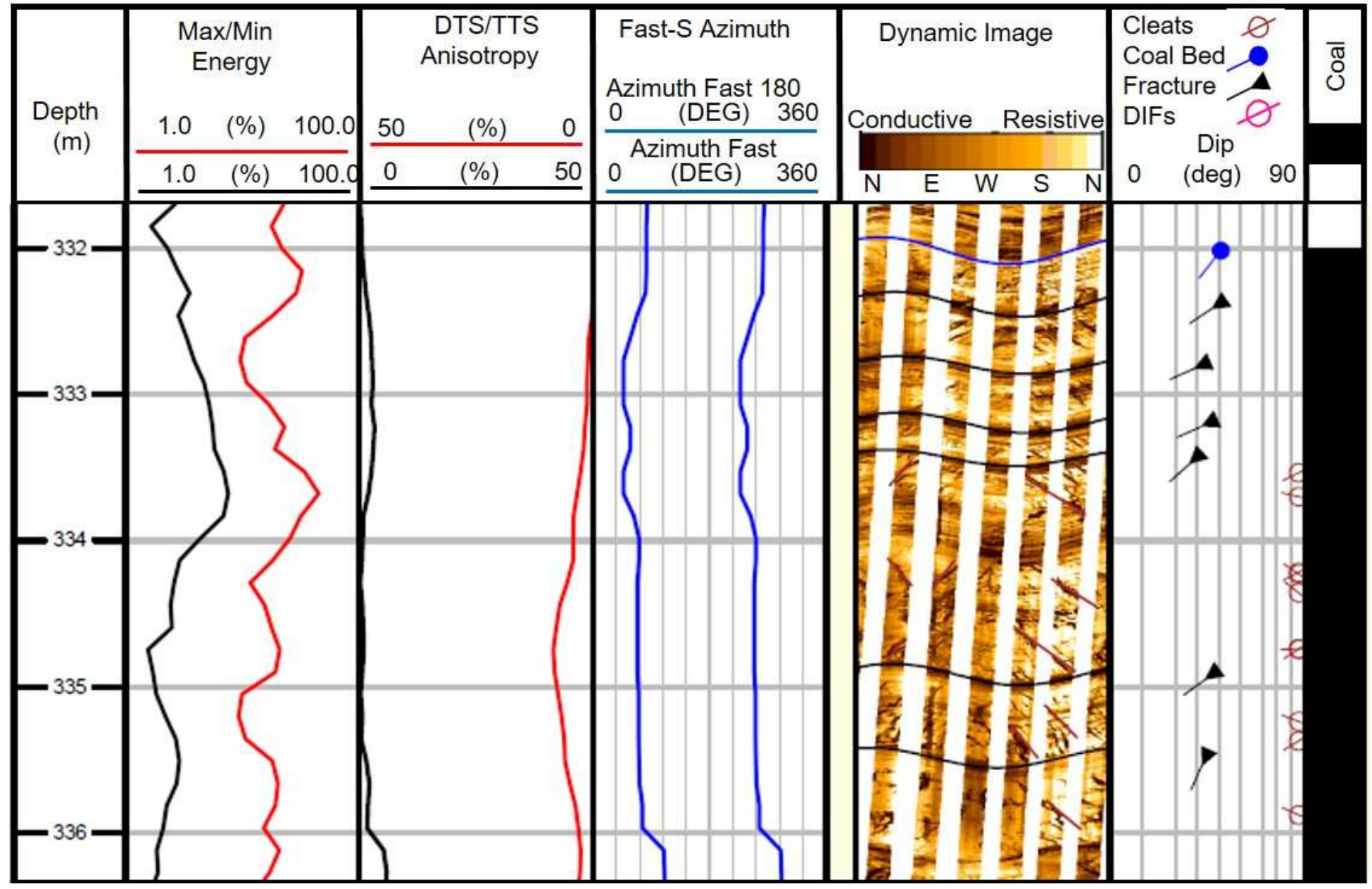

Figure 10

Anisotropy analysis representing seam-VIII in well W-2 illustrates maximum and minimum energy (\%), DTS and TTS anisotropy (\%), fast and $180^{\circ}$ apart S-azimuth, resistivity image with dip. 


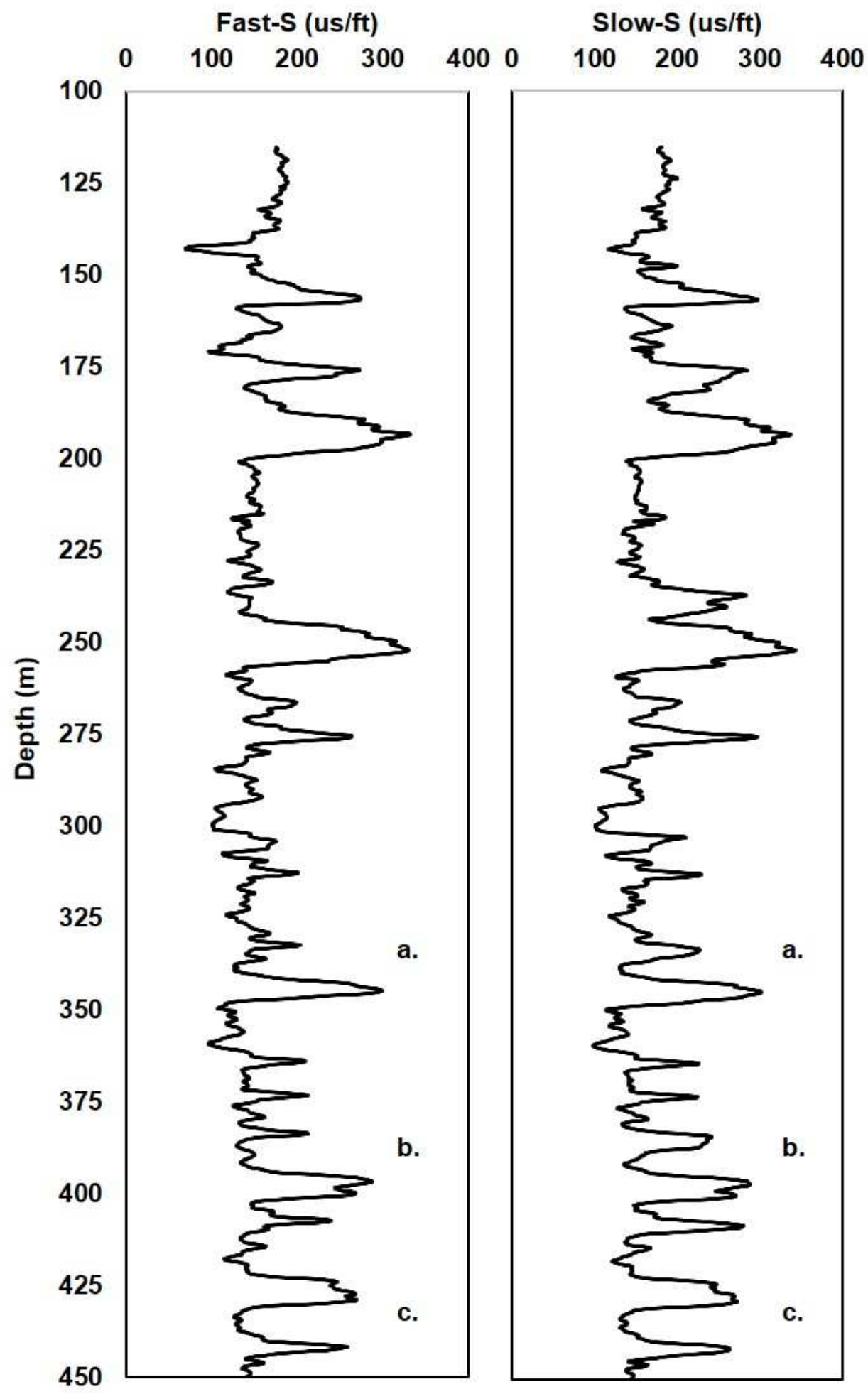

Figure 11

Fast and slow S-wave slowness (us/ft) from depth interval 115.0-450.0 $\mathrm{m}$ in well W-2 and 03 points (a, b, c) marked in the log for anisotropy characterization. 

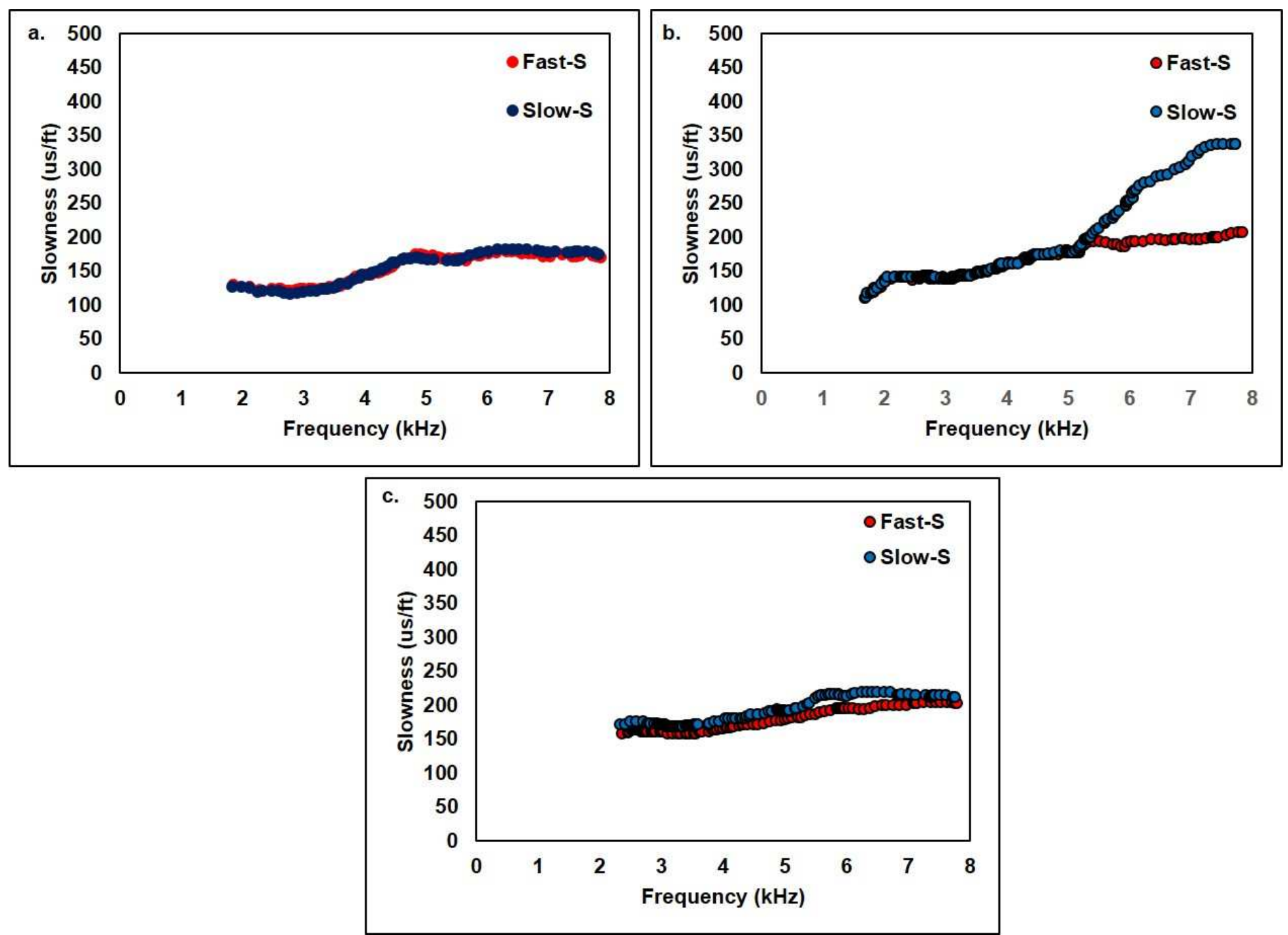

Figure 12

Slowness vs. frequency dispersion plot of fast (red) and slow (blue) S-wave at three depths: (a) Homogeneous isotropic formation at depth $342.0 \mathrm{~m}$ (b) Stress-induced fractured coal seam-V with inhomogeneous anisotropic characteristics at depth $389.0 \mathrm{~m}$ (c) Intrinsic anisotropy for homogeneous anisotropic formation at depth $437.0 \mathrm{~m}$. 


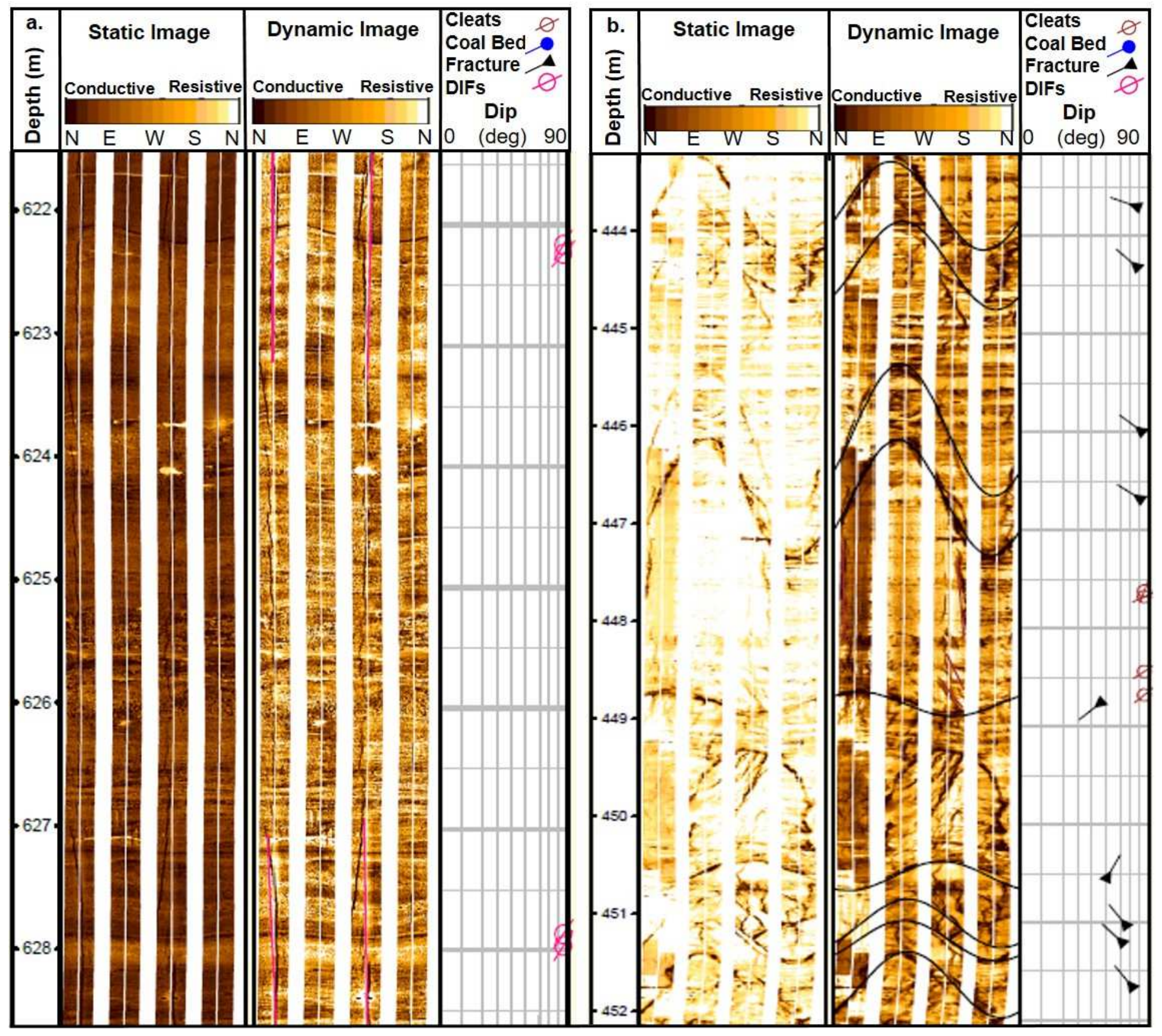

Figure 13

Static and dynamic resistivity image in well W-4 (a) represents DIFs with dip magnitude and direction from $622.0-628.0 \mathrm{~m}$, (b) represents dip magnitude and direction of fractures and cleat in seam- $\mathrm{V}$ from depth interval 444.0-452.0 m. 


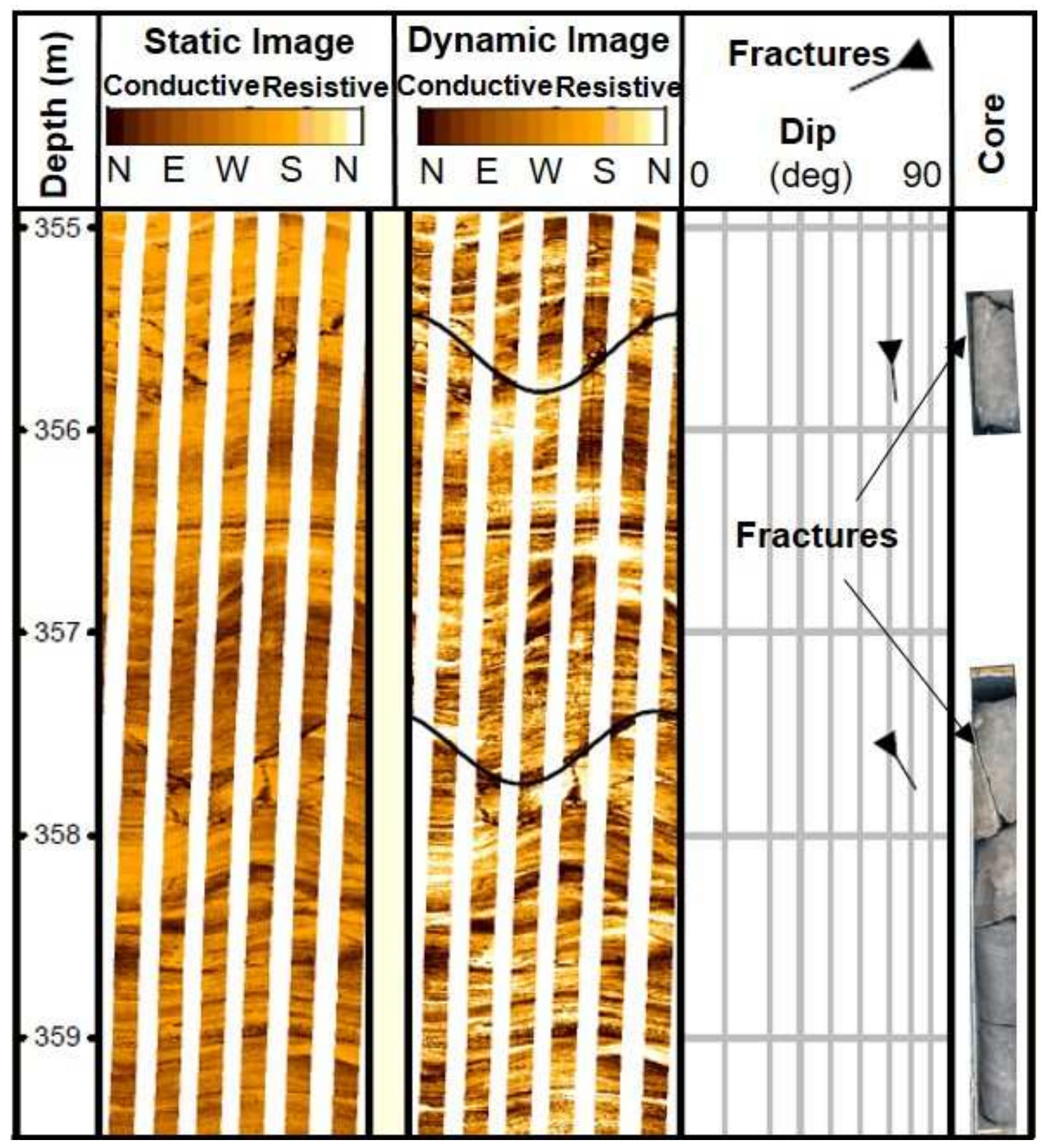

Figure 14

Correlation of fractures at $356.0 \mathrm{~m}$ and $357.5 \mathrm{~m}$ between drilling core and resistivity image log from depth $356.0 \mathrm{~m}$ to $362.5 \mathrm{~m}$. 

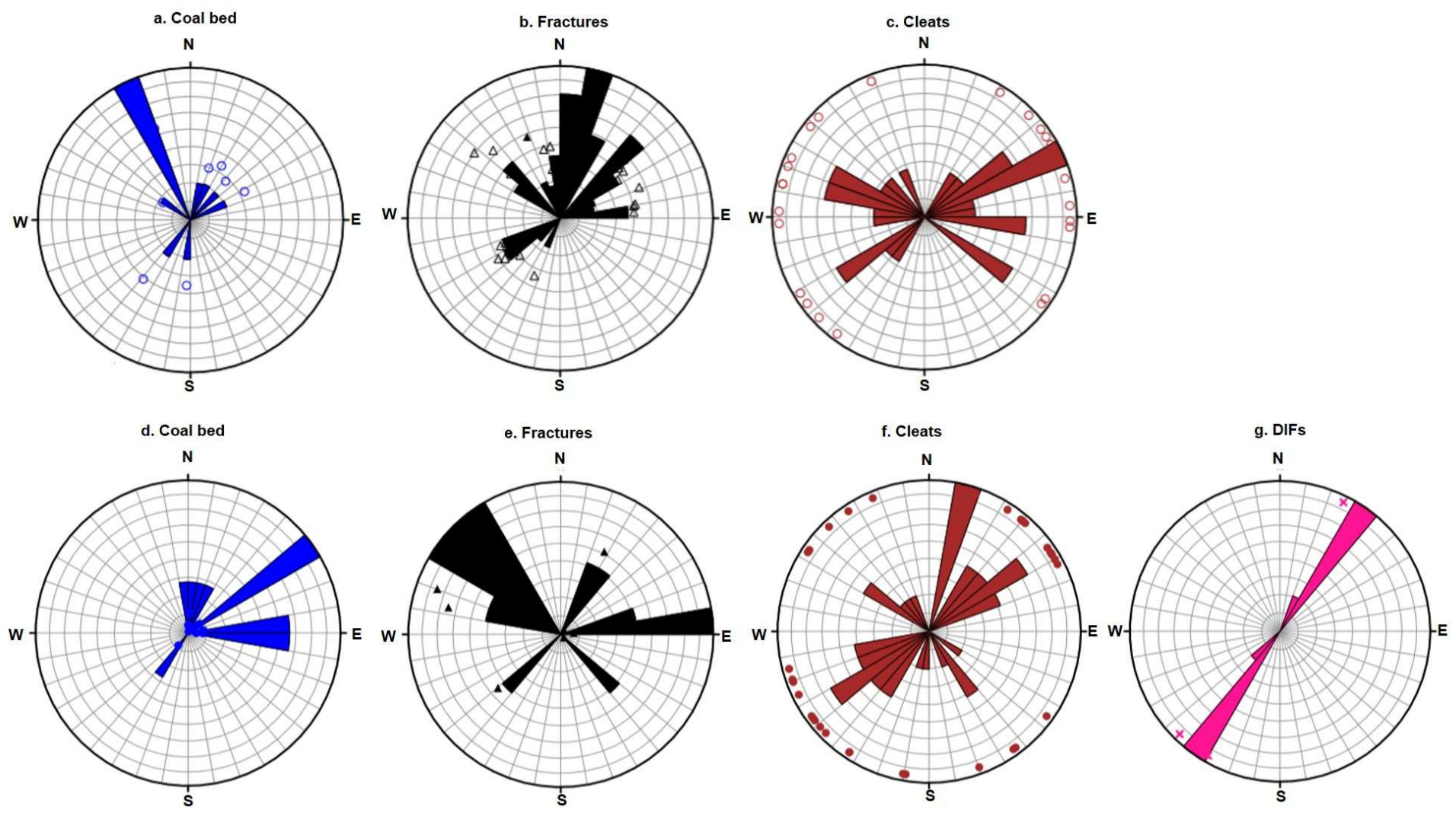

Figure 15

Stereonet plot representing dip magnitude and direction of 05 seams $(\mathrm{V}, \mathrm{VI}+\mathrm{VII}, \mathrm{VIII}, \mathrm{IX}, \mathrm{X})$ in well W-2 (a) fracture (b) cleats (c) coal bed; and in well W-4 (d) fracture (e) cleats (f) coal bed, (g) DIFs. 


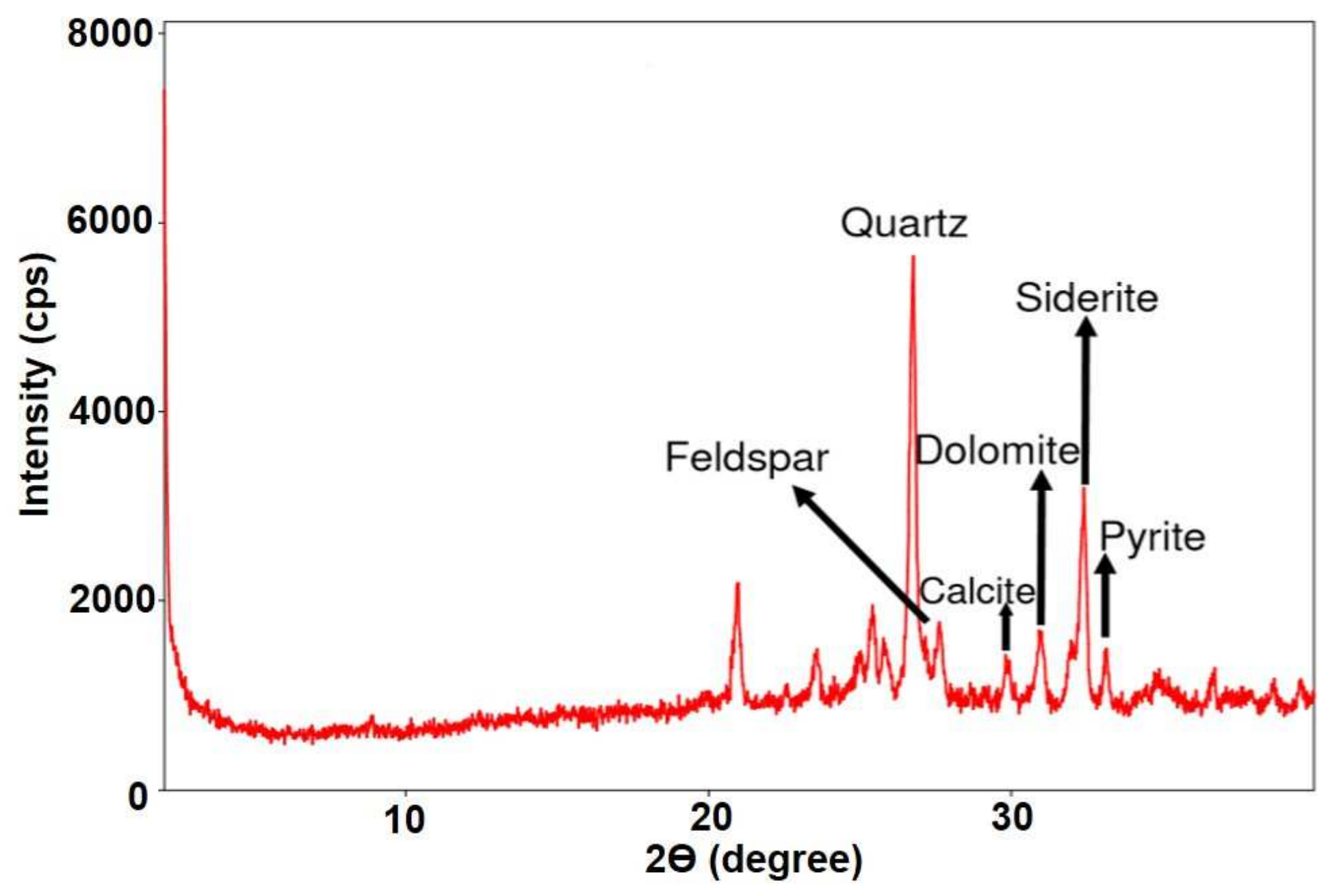

Figure 16

Cross-plot of intensity (cps) versus $2 \rrbracket$ (degree) from the XRD studies of SWC at $418.0 \mathrm{~m}$ in well A-1 showing the presence of siderite and pyrite. 